\title{
Novel functions of acyl-CoA thioesterases and acyltransferases as auxiliary enzymes in peroxisomal lipid metabolism.
}

\author{
Mary Hunt \\ Technological University Dublin, mary.hunt@tudublin.ie \\ Stefan Alexson \\ Karolinska Institute
}

Follow this and additional works at: https://arrow.tudublin.ie/scschbioart

Part of the Biochemistry Commons, Bioinformatics Commons, Congenital, Hereditary, and Neonatal Diseases and Abnormalities Commons, Molecular Biology Commons, and the Nutritional and Metabolic Diseases Commons

\section{Recommended Citation}

Hunt, M., Alexson, S. (2008) Novel functions of acyl-CoA thioesterases and acyltransferases as auxiliary enzymes in peroxisomal lipid metabolism. Progress in Lipid Research - 47(2008) 405-421. doi:10.1016/ j.plipres.2008.05.001

This Review is brought to you for free and open access by the School of Biological Sciences at ARROW@TU Dublin. It has been accepted for inclusion in Articles by an authorized administrator of ARROW@TU Dublin. For more information, please contact arrow.admin@tudublin.ie, aisling.coyne@tudublin.ie,gerard.connolly@tudublin.ie.

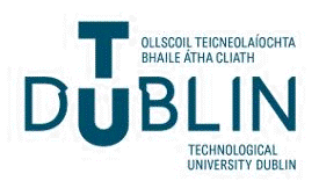




\title{
Novel functions of acyl-CoA thioesterases and acyltransferases as auxiliary enzymes in peroxisomal lipid metabolism.
}

\author{
*Mary C. Hunt and \#Stefan E. H. Alexson* \\ *Department of Genetics, Microbiology and Toxicology, Arrhenius Laboratory, \\ Stockholm University, Svante Arrhenius väg 16F, SE-106 91 Stockholm, Sweden and \\ \#Karolinska Institutet, Department of Laboratory Medicine, Division of Clinical \\ Chemistry, C1-74, Karolinska University Hospital at Huddinge, SE-141 86 Stockholm, \\ Sweden
}

*Corresponding author: Mary Hunt

E-mail: mary.hunt@gmt.su.se

Phone: +46 8-164162

Fax: +46 8-16 4315

Running title: Peroxisomal acyl-CoA thioesterases/acyltransferases

Keywords: Acyl-CoA thioesterases, peroxisomes, acyl-CoA, acyltransferases, coenzyme A, alpha oxidation, beta oxidation, omega oxidation. 


\begin{abstract}
Peroxisomes are single membrane bound organelles present in almost all eukaryotic cells, and to date have been shown to contain approximately 60 identified enzymes involved in various metabolic pathways, including the oxidation of a variety of lipids. These lipids include very long-chain fatty acids, methyl branched fatty acids, prostaglandins, bile acid precursors, and xenobiotics that are either $\beta$-oxidized or $\alpha$-oxidized in peroxisomes. The recent identification of several acyl-CoA thioesterases and acyltransferases in peroxisomes has revealed their various functions in acting as auxiliary enzymes in $\alpha$ - and $\beta$-oxidation in this organelle. To date, 9 functional acyl-CoA thioesterases and acyltransferases have been identified in mouse and 4 functional acyl-CoA thioesterases and acyltransferases in human, thus these enzymes make up a substantial portion of peroxisomal proteins. This review will therefore focus on new and emerging roles for these enzymes in assisting with the oxidation of various lipids, amidation of lipids for excretion from peroxisomes, and in controlling coenzyme A levels in peroxisomes.
\end{abstract}




\section{Contents}

\section{Introduction}

\section{Identification and characterization of acyl-CoA thioesterases in peroxisomes}

2.1 Characterization of peroxisomal acyl-CoA thioesterases

2.1.1 The Type-I family of acyl-CoA thioesterases

2.1.2. ACOT8 is a peroxisomal ACOT with very broad substrate specificity and possibly functions in regulation of intraperoxisomal CoASH levels

2.1.3 ACOT12 is a short-chain ACOT that may be involved in acetate formation from peroxisomal $\beta$-oxidation

\section{Role of acyl-CoA thioesterases as auxiliary enzymes in regulation of peroxisomal}

\section{$\alpha$ - and $\beta$ - oxidation}

3.1 An overview of peroxisomal $\beta$-oxidation

3.1.1 Peroxisomes contain lipid-binding proteins that influence ACOT activity and $\beta$-oxidation.

3.2 Acyl-CoA thioesterases and carnitine acyltransferases are differently expressed and may promote production of different metabolites in different organs.

3.2.1. Acyl-CoA thioesterases in regulation of coenzyme A (CoASH) levels in peroxisomes

3.2.2. Involvement of ACOT4 and ACOT8 in regulation of peroxisomal $\beta$ oxidation of dicarboxylic acids

3.2.3. ACOT6 in regulation of methyl branched lipid oxidation

3.2.4. Acyl-CoA thioesterases and synthesis of polyunsaturated fatty acids 
4. The acyltransferases involved in conjugation (amidation) of bile acids and fatty acids in peroxisomes

4.1 The acyl-CoA:amino acid N-acyltransferase gene cluster

4.1.1. Peroxisomes contain a bile-acid conjugating enzyme catalyzing the terminal step in bile acid synthesis.

4.1.2. Peroxisomes contain two putative acyl-CoA:amino acid $N$-acyltransferases that conjugate fatty acids and possibly other carboxylic acids

\section{Regulation of peroxisomal acyl-CoA thioesterases and acyltransferases}

5.1. Regulation of Acots and acyltransferases in peroxisomes

\section{Concluding remarks and perspectives}

7. Acknowledgements

8. References

\section{Introduction}

Peroxisomes are nearly ubiquitous organelles present in fungi, yeast, plant and animal cells. The peroxisome received its name in the 1960's from the pioneering work of Christian de Duve and co-workers [1]. The discovery by Goldfischer et al. in 1973 that peroxisomes are involved in certain human diseases [2] paved the way for the discovery 
of the importance of peroxisomes in the oxidation of various types of lipid molecules. One of the milestones in peroxisome research was the identification of a fatty acid $\beta$ oxidation system in mammalian peroxisomes (distinct from the mitochondrial $\beta$ oxidation system), and this led to a boost in research that revealed a discrete set of enzymes that catalyze the degradation of a variety of lipids (for reviews see [3-5]). These studies showed that rat and mouse liver peroxisomes contain three acyl-CoA oxidases which identified separate pathways for $\beta$-oxidation of different lipids in peroxisomes. These acyl-CoA oxidases catalyze the $\beta$-oxidation of straight-chain acyl-CoAs (catalyzed by acyl-CoA oxidase 1 , ACOX1), $\beta$-oxidation of the side-chain of bile acid precursors (catalyzed by ACOX2) and methyl branched-chain CoA esters (catalyzed by ACOX3). It is now well established that peroxisomes have many metabolic roles including $\beta$ oxidation, $\alpha$-oxidation, glyoxylate metabolism, ether-phospholipid synthesis, cholesterol and isoprenoid metabolism and bile acid synthesis. There are numerous existing reviews regarding the biochemistry of peroxisomes, peroxisome biogenesis and peroxisomal disorders [6-11], therefore these aspects will not be discussed in detail in this review. The recent identification and characterization of acyl-CoA thioesterases (ACOTs) and acyltransferases has now established distinct roles for these enzymes in peroxisomes and the current review will focus on these novel functions of these proteins as auxiliary enzymes in peroxisomal lipid metabolism. There are currently six ACOTs characterized in mouse peroxisomes, but only two in human peroxisomes. A family of related acyltransferases has also been identified in mouse and rat peroxisomes, with three acyltransferases in mouse, whereas human peroxisomes contain only one functional acyltransferase. This review will firstly focus on the identification of these enzymes, 
followed by a discussion as to their metabolic functions as auxiliary enzymes in peroxisomes. A list of currently identified ACOT and acyltransferase enzymes in mouse and human peroxisomes are given in Table I and II respectively, together with the current and previous nomenclature, tissue expression and substrate specificity.

\section{Identification and characterization of acyl-CoA thioesterases in peroxisomes}

\subsection{Characterization of peroxisomal acyl-CoA thioesterases}

ACOT activity was first identified as early as the 1950's, with the partial purification of a succinyl-CoA thioesterase from pig heart [12]. Since then several different families of ACOTs have been identified and characterized, as reviewed in [13]. As these genes were cloned by various groups, they were all given different names which led to confusion, and therefore a recent nomenclature has been introduced, in which the gene name is Acot and the genes are numbered sequentially [14]. The reaction carried out by ACOTs involves the cleavage of the thioester bond of acyl groups attached to coenzyme A, to release the free acid and free CoASH (Fig. 1A). The acyl group can vary and have been identified as long-, medium- and short-chain fatty acids, dicarboxylic acids, branched chain fatty acids or bile acids, depending on the ACOT enzyme involved. The second group of enzymes reviewed here are the acyl-CoA:amino acid $\mathrm{N}$-acyltransferases, which catalyze the transfer of carboxylic acids from CoASH to an amino acid, usually taurine or glycine (Fig. 1B and 1C). 


\subsubsection{The Type-I family of acyl-CoA thioesterases}

Initial interest in ACOT activity in rodent stems from the findings that the activity is highly inducible in livers of rats treated with peroxisome proliferators, such as fibrates that act as hypolipidemic agents. Subcellular fractionation of rat livers showed that the activity is mainly increased in mitochondria, cytosol and peroxisomes by these compounds [15-18]. Peroxisome proliferators act as hypolipidemic agents in part by increasing fatty acid degradation via activation of peroxisome proliferator-activated receptor alpha (PPAR $\alpha)$, which is a lipid activated transcription factor that is a key regulator of genes involved in fatty acid metabolism [19]. The increase in ACOT activity by PPAR $\alpha$ activators suggested that these enzymes may be beneficial for fatty acid degradation (regulation of expression of the ACOT enzymes will be discussed in more detail in section 5). Biochemical analysis of highly purified peroxisomes revealed ACOT activity with short, medium and long-chain acyl-CoAs (from $\mathrm{C}_{2}-\mathrm{C}_{20}-\mathrm{CoA}$ ) $[20,21]$ and partial purification of a peroxisomal ACOT revealed a long-chain acyl-CoA thioesterase activity [20]. A similar long-chain ACOT activity was purified from rat liver mitochondria and cytosol and at that time, an antibody raised against a purified mitochondrial acyl-CoA thioesterase (ACOT2, formerly known as MTE-I), identified structurally related proteins in mitochondria, cytosol and peroxisomes, suggesting a related protein family $[22,23]$. In the genomic era, the cloning of specific genes was carried out, which resulted in the identification of several distinct peroxisomal acyl-CoA thioesterases. One particular gene family that was identified at that time was named the Type-I acyl-CoA thioesterase gene family, which based on enzyme activity measurements and Western blot analysis was suggested to code for closely related 
enzymes in cytosol, mitochondria and peroxisomes [20, 22]. Subsequent molecular cloning of this gene family identified a cluster of six related genes, localized on chromosome 12 D3 in mouse [24-27] (Fig. 2). Four of these six genes code for enzymes that localize in peroxisomes as they all contain peroxisomal type 1 targeting signals (PTS1) at their carboxyterminal ends. In mouse, these four peroxisomal acyl-CoA thioesterases are named ACOT3, 4, 5 and 6, which show approximately $65-80 \%$ sequence identity to eachother. These four proteins end -AKL (ACOT3 and ACOT5), CRL (ACOT4) and -SKL (ACOT6) (Fig. 2), which targets them to peroxisomes as confirmed in all cases using green fluorescent fusion protein experiments [25-27]. The open reading frames of all four genes are encoded by three exons and the exon/intron boundaries are conserved in this gene family. The ACOT3 and ACOT5 show the highest degree of sequence similarity $(82 \%)$ and were therefore characterized simultaneously in a study in 2004 [26]. Expression of the recombinant proteins revealed that ACOT3 is a long chain acyl-CoA thioesterase (highest activity with $\mathrm{C}_{14}-\mathrm{C}_{18}$-CoA, whereas ACOT5 is a medium chain acyl-CoA thioesterase (highest activity with $\mathrm{C}_{10}$-CoA). Interestingly, ACOT3 and ACOT5 had little or no activity towards 3-hydroxy-palmitoyl-CoA, an intermediate in peroxisomal $\beta$-oxidaiton, suggesting that these enzymes hydrolyze the substrates/products of $\beta$-oxidaiton, but not intermediates in the pathway [26]. Acot3 mRNA is expressed as two splice variants, which show a tissue-specific expression in liver and kidney [26]. In contrast, Acot5 is mainly expressed in white adipose tissue and brain [28]. 
The ACOT4 shows the lowest percentage sequence similarity to the other peroxisomal thioesterases $(65 \%)$ and indeed was the first thioesterase to reveal a more 'specific' substrate specificity, being active only with succinyl-CoA $\left(\mathrm{K}_{\mathrm{m}} \approx 13 \mu \mathrm{M}\right)$ and glutaryl-CoA $\left(\mathrm{K}_{\mathrm{m}} \approx 37 \mu \mathrm{M}\right)$ [25], suggesting a role in dicarboxylic acid metabolism. The mouse Acot4 mRNA is expressed mainly in liver, kidney and proximal intestine, with the former two organs being involved in dicarboxylic acid formation and metabolism. Interestingly, analysis of the gene cluster of the human Type-I ACOT genes revealed only one functional peroxisomal gene, encoded for by a homologue of mouse Acot4, which contains a carboxyterminal -PKL and is localized in peroxisomes (Fig. 2) [29]. This was a surprising finding, given that the mouse genome contained four peroxisomal Type-I ACOTs. However, functional analysis revealed that the human ACOT4 protein could in fact catalyze the hydrolysis of the same substrates as the combined activities of mouse ACOT3, ACOT4 and ACOT5 (i.e. long-chain acyl-CoAs, succinyl-CoA/glutaryl-CoA and medium-chain acyl-CoAs) [29], showing that evolution of the human genome resulted in an enzyme that apparently adopted the activities of three distinct mouse enzymes. In human, analysis of the genome also revealed the presence of a further gene on chromosome $19 q 13.12$, which showed $91 \%$ sequence identity to the human ACOT4 gene and contains a peroxisomal targeting signal of -PKL. However, this gene on chromosome 19 lacks introns and contains several stop codons, and is therefore likely a pseudogene, even though the mRNA is expressed as identified by ESTs in pancreatic islets, brain and placenta [29]. 
The final peroxisomal enzyme encoded for by the Type-I gene cluster in mouse was recently identified as ACOT6, a thioesterase that is apparently only active on phytanoylCoA and pristanoyl-CoA [27]. The corresponding mRNA is mainly expressed in white adipose tissue, where it is co-expressed with Acox 3 , the rate-limiting enzyme in branched chain acyl-CoA oxidation. In human, there is a homologue of the mouse Acot6, which is however unlikely to code for a functional protein as this gene appears to be transcribed from the second exon, and translated from an ATG at the end of exon 2, therefore resulting in a much shorter peptide [29]. The human ACOT6 contains a carboxyterminal tripeptide of -SKI, which localizes in the cytosol in human skin fibroblasts, when fused to green fluorescent protein [29].

Searches in databases suggest that homologues of these Type-I family of Acot genes are widespread in animals from nematodes to human, but are not found in yeast, fungi, plants or insects. Sequence analysis, secondary structure predictions and site-directed mutagenesis experiments identified the Type-I ACOTs as members of the $\alpha / \beta$-hydrolase protein superfamily, members of which contain a lipase/esterase active site motif that is characterized by a conserved serine residue located in a GlyXaaSerXaaGly motif (GxSxG) [30]. In addition these $\alpha / \beta$-hydrolases contain a conserved histidine residue and an aspartic/glutamic acid residue, which together with the nucleophile constitute a catalytic triad in this protein family.

2.1.2. ACOT8 is a peroxisomal ACOT with very broad substrate specificity and possibly functions in regulation of intraperoxisomal CoASH levels 
A further peroxisomal acyl-CoA thioesterase named ACOT8, (previously known as PTE2, PTE1 or hACTEIII/hTE), has also been characterized, which is not related to the TypeI gene family discussed above. This enzyme was initially identified by a yeast two-hybrid screening as a protein that interacted with, and activated, the HIV-1 Nef protein $[31,32]$. Nef is a $27-\mathrm{kDa}$ myristoylated cytoplasmic protein that is involved in CD4 downregulation and it was suggested that interaction of ACOT8 and Nef assisted in mediation of Nef-induced CD4 down-regulation. Nef is not a bona fide peroxisomal protein, but apparently "piggy-backs" into peroxisomes by interacting with ACOT8, although only in about $10-20 \%$ of the cells examined [33]. The human ACOT8 and its yeast counterpart Ptel were identified by Jones et al. in 1999 as peroxisomal proteins, and deletion of the yeast Ptel resulted in impaired growth on fatty acids, implying a role for this gene in fatty acid oxidation [34]. The yeast Ptel had significant thioesterase activity with decanoyl-CoA, however the substrate specificity was not studied for the human enzyme at this time. It is of interest to note that knockdown of the Ptel in yeast resulted in the loss of about $80 \%$ of the decanoyl-CoA thioesterase activity in yeast extracts, suggesting that Ptel accounts for the majority of the thioesterase activity in yeast. The yeast Ptel was further characterized by Maeda et al in 2006 and shown to hydrolyze short and medium straight chain and branched chain acyl-CoAs, and thereby was shown be involved in synthesis of polyhydroxy-alkanoates (PHA) and in $\beta$-oxidation in yeast [35]. In Arabidopsis thaliana, the ACOT8 homologue, called ACH2, contains a carboxyterminal -SKL and is therefore likely also a peroxisomal enzyme [36]. The cloned A. thaliana enzyme is active on long-chain saturated and unsaturated acyl-CoAs, 
but was insensitive to feedback inhibition by CoA even up to $100 \mu \mathrm{M}$, and it was suggested that $\mathrm{ACH} 2$ is unlikely to have a role in fatty acid oxidation in plants. Yeast does not contain any homologues to the Type-I ACOTs or ACOT12 (described in section 2.1.3), and therefore it is likely that the only yeast peroxisomal thioesterase is Ptel.

Further characterization of the ACOT8 enzyme in mouse and rat identified it as an acylCoA thioesterase, which hydrolyzes a very wide variety of CoASH esters $[25,37,38]$. In fact ACOT8 hydrolyzes all acyl-CoA esters tested so far, indicating that this enzyme likely recognizes the CoA moiety of the substrate for binding and not the acyl-chain. In support of this, to date ACOT8 is one of only two peroxisomal ACOT enzymes regulated by free $\mathrm{CoASH}$ with an estimated $\mathrm{IC}_{50}$ of $\sim 10-15 \mu \mathrm{M}$ [37]. As the human ACOT8 enzyme shows about $80 \%$ sequence identity to the rat [38] and mouse [37] enzymes, it is likely that the human ACOT8 also hydrolyzes a wide variety of acyl-CoA substrates. Interestingly, over-expression of human ACOT8 in murine and human T-cell lines resulted in an up-regulation of peroxisomal biogenesis, further supporting a link between metabolic activity and peroxisome proliferation [39]. Crystallization of the Escherichia coli homolog of ACOT8 (E. coli thioesterase II) identified a 'double hot dog' tertiary fold, with a novel catalytic site containing aspartic acid, glutamine and threonine [40]. This is in fact one of the few crystal structures currently available for homologues of the mammalian ACOT enzymes, however work is currently underway to crystallize several of these mammalian proteins. In $E$. coli however, there are seven different hot dog thioesterases encoded by the E. coli genome that have a known X-ray structure, the biological function is only known in the case of one thioesterase [41]. 
2.1.3 ACOT12 is a short-chain ACOT that may be involved in acetate formation from peroxisomal $\beta$-oxidation

ACOT12 is the most recently identified peroxisomal ACOT, which is active on short chain acyl-CoAs. This enzyme was originally identified as an extra-mitochondrial short chain thioesterase with highest activity with acetyl-CoA, and some activity also with butyryl-CoA and hexanoyl-CoA [42-44]. ACOT12 is a protein of 555 amino acids in human (556 in mouse), and mouse and rat proteins contain a variant of the type 1 peroxisomal targeting signal of $-\mathrm{SVL}$. However, the carboxyterminal of human ACOT12 ends -STF [45], suggesting that in rodents the protein is peroxisomal, but this may not be the case in human. Previous work using subcellular fractionation and Western blotting revealed the protein and activity in peroxisomal fractions in rat liver, suggesting that ACOT12 is indeed a peroxisomal protein, or that at least it may have a dual localization in peroxisomes and cytosol [46]. In addition, a very recent proteomics study on mouse kidney peroxisomes also identified ACOT12 in peroxisomes [47]. ACOT12 shows some interesting features that clearly distinguishes it from the other peroxisomal ACOTs. ACOT12 is a $62 \mathrm{kDa}$ protein that contains two thioesterase domains with homology to bacterial thioesterases and some other mammalian ACOTs (but not to the Type-I ACOTs), and a C-terminal part that contains a steroidogenic acute regulatory proteinrelated lipid transfer (START) domain [45], which is likely to be involved in lipid binding. The enzyme appears to be an acetyl-CoA thioesterase, with lower activities with propionyl-CoA and butyryl-CoA [42]. Also, the enzyme activity is activated by ATP and 
inhibited by ADP [48] indicating a possible metabolic regulation of acetate production by nucleotide levels in peroxisomes. The rat ACOT12 enzyme is also inhibited by free CoASH (approx. 80\% inhibition at $40 \mu \mathrm{M}, \mathrm{IC}_{50}$ approx $10 \mu \mathrm{M}$ ) [48], making ACOT12 and ACOT8 the only two peroxisomal thioesterases currently identified that are regulated by free CoASH.

In summary of the above, mouse contains six currently characterized peroxisomal ACOTs, namely ACOT3, ACOT4, ACOT5, ACOT6, ACOT8 and ACOT12, whereas human contains only two, ACOT4 and ACOT8. The revised nomenclature and the substrate specificities of these enzymes is shown in Table I (mouse) and Table II (human). It is intriguing that in particular rodents contain a number of ACOTs with distinct substrate specificities, which indicate that these enzymes play important roles in regulation of peroxisomal lipid metabolism.

\section{Role of acyl-CoA thioesterases as auxiliary enzymes in regulation of peroxisomal $\alpha$ - and $\beta$ - oxidation}

\subsection{An overview of peroxisomal $\beta$-oxidation}

Peroxisomal $\beta$-oxidation of carboxylic acids is generally believed to act as a chainshortening system and thereby provide mitochondria with suitable substrates. Alternatively, the peroxisomal $\beta$-oxidation may be considered to function as a detoxification system to metabolize carboxylic acids into more water-soluble products that can be excreted. In addition to the physiological CoA esters that undergo $\beta$-oxidation 
in peroxisomes, such as very long-chain fatty acids, bile acid intermediates, eicosanoids, and methyl branched fatty acids, also some xenobiotic carboxylic acids undergo $\beta$ oxidation in peroxisomes (for review, see [49]). Most of the carboxylic acids are activated to the corresponding $\mathrm{CoA}$ ester outside the peroxisome by acyl-CoA synthetases localized in the peroxisomal membrane or in the endoplasmic reticulum [50], and most likely the CoA ester is being transported across the peroxisomal membrane via a family of ATP-binding-casette transporters (ABC transporters). To date, four peroxisomal $\mathrm{ABC}$ half-transporters have been identified, which have been recently discussed in detail in a mini-review by Kemp et al [51]. ABCD1 is involved in the transport of very long chain acyl-CoAs into peroxisomes and mutations in this protein result in X-linked adrenoleukodystrophy [52]. ABCD3 is proposed to be involved in transport of long chain acyl-CoAs [53], but recently, unpublished data referred to in [54] stated that $A b c d 3$-knockout mice were found to accumulate bile acid precursors and branched chain fatty acids, suggesting that this transporter may be involved in transfer of these CoA esters into the peroxisome. Inside the peroxisomal matrix, there is a dedicated set of enzymes that $\beta$-oxidize these CoA esters. The first step in peroxisomal $\beta$-oxidation is carried out by an acyl-CoA oxidase (ACOX), and rodents contain three acyl-CoA oxidase enzymes [55-57], which dehydrogenate straight-chain acyl-CoAs, branched chain acyl-CoAs and the bile acid intermediates trihydroxycoprostanoyl-CoA and dihydroxycoprostanoyl-CoA, respectively. Human contains only two ACOX enzymes catalyzing straight-chain and branched-chain acyl-CoA dehydrogenation, respectively $[58,59]$. The second and third steps in peroxisomal $\beta$-oxidation are catalyzed by multifunctional enzymes MFP1 or MFP2 (L- or D- bifunctional proteins) [60-62]. The 
final step in peroxisomal $\beta$-oxidation involves a thiolytic cleavage of the acyl-CoA catalyzed by either 3-ketoacyl-CoA thiolases a or b, or SCPx [63-65], resulting in the release of a chain-shortened acyl-CoA and acetyl-CoA or propionyl-CoA, depending on the substrate initially oxidized. The 2 carbon acetyl-CoA is released during the $\beta$ oxidation of very long chain acyl-CoAs, branched chain acyl-CoAs and dicarboxylylCoAs, whereas propionyl-CoA is released during $\beta$-oxidation of branched chain acylCoAs and bile acid intermediates.

As stated above, the peroxisomal $\beta$-oxidation of substrates results in chain-shortening of carboxylic acids, with the concomitant release of acetyl-CoA or propionyl-CoA, and hence the peroxisome requires a system to remove fatty acids from the $\beta$-oxidation process. There are three possible routes for the removal of fatty acids, namely formation of carnitine esters, which can be transferred to mitochondria for further oxidation, conjugation to glycine/taurine by acyltransferases (e.g. bile acid and fatty acid conjugation) for excretion into bile or blood, or alternatively hydrolysis to the free acid by ACOT enzymes for transport to mitochondria or excretion in urine. The involvement of ACOTs, carnitine acyltransferases and acyl-CoA:amino acid $N$-acyltransferases in these routes is shown in Fig. 3 and will be discussed below.

3.1.1 Peroxisomes contain lipid-binding proteins that influence ACOT activity and $\beta$ oxidation . 
Peroxisomes contain two lipid-binding proteins that potentially provide additional regulation to peroxisomal fatty acid metabolism. Almost 30 years ago, sterol carrier protein-2 (SCP2) was purified as a soluble sterol carrier, but was later shown to localize to peroxisomes via a PTS1 signal. Several findings since then have changed the view on the function of SCP2 in peroxisomal lipid metabolism, as reviewed in [66]. Subsequent characterization of the functions of this protein in various experimental systems suggest that SCP2 may act as an acyl-CoA binding protein that can interact with enzymes of the peroxisomal $\beta$-oxidation system. This could serve several purposes, for example delivery of acyl-CoA's to the degradation pathway, which may provide a mechanism for increased efficiency for fatty acid oxidation in peroxisomes and possibly also protect acyl-CoAs' from hydrolysis by ACOT's. Very recently Antonenkov et al showed that in addition to it's well known cytosolic localization, the liver fatty acid binding protein (L-FABP) is also a bona fide peroxisomal protein [67]. Although it appears that only a small fraction of L-FABP is present in peroxisomes under normal (control) conditions, the amount is strongly increased by fibrate treatment. It was also demonstrated that addition of purified L-FABP to isolated peroxisomes stimulated $\beta$-oxidation of palmitoyl-CoA at higher substrate concentrations, presumably preventing substrate inhibition. Similarly, ACOT activity was also stimulated by the addition of L-FABP, probably via a similar mechanism by preventing substrate inhibition. The presence in peroxisomes of lipid binding proteins and the ACOT's point to regulatory functions for these proteins in peroxisomal lipid metabolism, but it is not yet known how these proteins interact. 
3.2 Acyl-CoA thioesterases and carnitine acyltransferases are differently expressed and may promote production of different metabolites in different organs.

Peroxisomes contain ACOTs and carnitine acyltransferases with similar acyl-CoA substrate specificities, which raises questions as to their roles in fatty acid metabolism. Carnitine acyltransferases are a group of enzymes that catalyze the reversible transfer of acyl-CoAs of varying chain-lengths to carnitine. Peroxisomes contain two distinct carnitine acyltransferases, carnitine octanoyltransferase (CROT) and carnitine acetyltransferase (CRAT) [68, 69], and it was generally believed that formation of carnitine esters was the terminal reaction in peroxisomes to produce shorter metabolites that could be transported to mitochondria for further oxidation. CROT catalyzes the transfer of medium chain $\left(\mathrm{C}_{6}-\mathrm{C}_{10}\right)$ acyl-CoAs and methyl branched medium-chain acylCoAs, such as dimethylnonanoyl-CoA (DMN-CoA), to carnitine [70, 71]. CRAT has been characterized as a short chain carnitine acyltransferase, with highest activity with butyryl-CoA, followed by propionyl-CoA and acetyl-CoA [71]. CRAT purified from mouse liver has a $\mathrm{K}_{\mathrm{m}}$ of $\approx 20 \mu \mathrm{M}$ with short chain acyl-CoA's, whereas CROT has a $\mathrm{K}_{\mathrm{m}}$ of $\approx 3.4 \mu \mathrm{M}$ with medium-chain acyl-CoAs (up to $\mathrm{C}_{12}$-CoA) and a higher $\mathrm{K}_{\mathrm{m}}$ towards longer chain acyl-CoAs [71].

The recent identification of ACOT's with distinct acyl-CoA specificities challenges this view and suggests that the free acids may also be terminal metabolites in peroxisomes. Peroxisomes contain two acyl-CoA thioesterases (ACOT12 and ACOT5), which are specific for short- and medium-chain acyl-CoA's respectively. Mouse ACOT5 was 
identified as a medium chain acyl-CoA thioesterase, preferentially hydrolyzing $\mathrm{C}_{8}-\mathrm{C}_{12}$ acyl-CoAs, with a $\mathrm{K}_{\mathrm{m}}$ value of $\approx 3 \mu \mathrm{M}$ [26]. In addition to ACOT5, ACOT8 hydrolyzes short- and medium-chain acyl-CoAs, with $\mathrm{K}_{\mathrm{m}}$-values of 3-30 $\mu \mathrm{M}$ depending on the substrate [37]. Peroxisomes contain the short chain acyl-CoA thioesterase ACOT12 as described in Section 2.1.3., which hydrolyzes short chain acyl-CoAs with a $\mathrm{K}_{\mathrm{m}}$ of $60-200$ $\mu \mathrm{m}[42,43]$. The presence of short and medium chain acyl-CoA thioesterases and carnitine acyltranserases in peroxisomes suggests that these enzymes would compete for the same substrate but produce different metabolites (ACOTs producing the free acid and the carnitine acyltransferases producing carnitine esters). However, a recent study into the mRNA expression of the acyltransferase and acyl-CoA thioesterase enzymes shows that these enzymes have in fact a very different tissue expression profile [28]. Therefore, depending on the tissue, either the free acid will be produced (by thioesterases) or the carnitine ester (by carnitine acyltransferases), suggesting that two complementary enzyme systems exist for the removal of acyl-CoA esters from the peroxisome rather than being competitive enzymes for the same substrate (Fig. 4). In line with this, it has been shown that peroxisomal $\beta$-oxidation in liver (studied in cultured hepatocytes) results in the production of free acetate [72] whereas in heart, free acetate does not appear to be a major metabolite produced by peroxisomal $\beta$-oxidation [73]. These findings can be explained by the different tissue expression of Crat and Acot12, since Acot12 is mainly expressed in liver, whereas Crat is expressed at very low levels in this tissue [28], thus resulting mainly in production of acetate in liver. In contrast, in heart the expression of Crat dominates, likely resulting in carnitine ester production for transfer to mitochondria, and less acetate production. This aspect of carnitine acyltransferase versus acyl-CoA 
thioesterase routes for production of carnitine esters or free acids has also recently been addressed by Wanders \& Komen, who suggested that in liver the thioesterase pathway is likely to dominate, whereas in human skin fibroblasts, production of carnitine esters is the most important route [74]. It should also be kept in mind that the relative importance of the free acid and carnitine ester pathways may depend on the physiological conditions regarding the degree of sequestration of $\mathrm{CoASH}$, which will also regulate the activity of ACOT8 and ACOT12. However, a further obvious function for CRAT may also be to transfer butyryl-CoA (which cannot be $\beta$-oxidized in peroxisomes) [75] to carnitine for further transport to mitochondria.

It is well established that peroxisomes also contain the medium-chain enzymes carnitine octanoyltransferase (CROT) and ACOT5, which would play similar roles to produce carnitine esters versus free acids, but using medium chain acyl-CoA's. Indeed CROT was recently demonstrated to transfer DMN-CoA (formed during $\beta$-oxidation of branched chain fatty acids) to DMN-carnitine, which can be transferred to the mitochondria for further oxidation [70]. The CROT enzyme is most highly expressed in liver and the proximal intestine, followed by kidney, with much lower expression in other tissues [28]. Again, the thioesterase (Acot5) shows a different tissue expression pattern, being most highly expressed in white adipose tissue and brain. These data therefore suggest that medium chain acyl-CoA's produced in peroxisomes in liver and intestine will be transferred to carnitine esters and presumably further on to mitochondria (Fig. 4). The importance of esterification to carnitine for transfer to mitochondria is not obvious in view of the fact that medium chain fatty acids apparently enter mitochondria in a 
carnitine independent manner, suggesting that medium chain fatty acids generated from the action of Acot5 could also be transferred to mitochondria. However, the strikingly different tissue expression pattern of Acot5, being most highly expressed in white adipose tissue and brain, suggests more specific functions for this enzyme in these tissues.

\subsubsection{Acyl-CoA thioesterases in regulation of coenzyme A (CoASH) levels in} peroxisomes

As discussed above, the substrates for $\beta$-oxidation most likely enter peroxisomes as the $\mathrm{CoA}$ ester via $\mathrm{ABC}$ half transporters, although this has not been proved for all substrates (for reviews see $[51,54]$ ). CoASH is also required for the last step of $\beta$-oxidation, the 3ketoacyl-CoA thiolase reaction, demonstrating a requirement for free CoASH in peroxisomes. Little up to date data is available on the intraperoxisomal concentration of CoASH, however in the 1980s total peroxisomal CoASH levels were estimated to be approximately $700 \mu \mathrm{M}$, with un-esterified CoA levels estimated at $230 \mu \mathrm{M}$ [76, 77]. The ratio of esterified to un-esterified CoASH may however vary under different physiological conditions such as fed and fasting states, higher levels of slowly oxidized carboxylic acids etc. The activity of the ACOT enzymes results in the hydrolysis of acylCoAs, with the concomitant release of the free fatty acid and free CoASH, suggesting a role for ACOT enzymes in the regulation of free CoASH levels in peroxisomes. As mentioned above, the only two ACOT enzymes identified to be regulated by free CoASH are the ACOT8, with an estimated $\mathrm{IC}_{50}$ of $10-15 \mu \mathrm{M}$ [37], and ACOT12 (with an estimated $\mathrm{IC}_{50}$ of about $10 \mu \mathrm{M}$ ) [48], whereas none of the enzymes ACOT3, 4, 5 or 6 
were inhibited by CoASH even at concentrations of $500 \mu \mathrm{M}$. Therefore it appears that ACOT8 and ACOT12 act as 'coenzyme A sensors' in peroxisomes and may be inhibited under conditions of 'low metabolic activity', assuming more unesterified CoASH under these conditions. However, during conditions when CoASH levels are low or become rate-limiting due to sequestration in peroxisomal $\beta$-oxidation (such as during fasting or possibly fibrate treatment), ACOT8 and ACOT12 would be activated, thus supplying $\mathrm{CoASH}$ required for the thiolase reaction. It should also be kept in mind that it is not clear if the peroxisomal content of unesterified CoASH is readily available since it was demonstrated that in isolated peroxisomes, unesterified CoASH appears to be bound to an $80 \mathrm{kDa}$ protein [78]. This would imply that ACOT8 and ACOT12 may in fact be active under most conditions (i.e. not inhibited due to low levels of free CoASH).

A further twist in the regulation of CoASH levels in peroxisomes involves two recently identified nudix hydrolase enzymes active on $\mathrm{CoASH}$ and $\mathrm{CoA}$ derivatives. The first of these enzymes is the NUDT7 identified in mouse peroxisomes in 2001 by Gasmi et al [79], which acts as a diphosphatase and cleaves CoASH and its derivatives (e.g. acetylCoA) with a $\mathrm{K}_{\mathrm{m}}$ of $\approx 240-430 \mu \mathrm{M}$, resulting in the production of 3',5'-ADP and 4'phosphopantetheine. NUDT7 homologues have also been cloned from yeast and $C$. elegans. The yeast $N u d t 7$ has a low $\mathrm{K}_{\mathrm{m}}(24 \mu \mathrm{M})$ for oxidized CoA (CoASSCoA), which is more than ten times lower than the $\mathrm{K}_{\mathrm{m}}$ for CoASH $\left(\mathrm{K}_{\mathrm{m}} \approx 280 \mu \mathrm{M}\right)$ [80], suggesting that in yeast it removes potentially toxic or non-functional oxidized $\mathrm{CoA}$ in peroxisomes. In C. elegans, the $\mathrm{K}_{\mathrm{m}}$ for free $\mathrm{CoASH}$ is $\approx 220 \mu \mathrm{M}$ and is similar to that of oxidized CoA at $\approx 320 \mu \mathrm{M}$, showing that this enzyme has no real preference for free or oxidized CoA [81]. 
Similar to the C. elegans enzyme, the mouse NUDT7 does not have a preference for oxidized CoA in-vitro as it hydrolyzes free CoA and oxidized CoA with a similar $\mathrm{K}_{\mathrm{m}}$ of around $230 \mu \mathrm{M}$ [79]. Further investigation by our group suggests that NUDT7 mainly metabolizes CoASH esterified to longer chain fatty acids (Reilly et al, manuscript submitted). Recently, a further novel peroxisomal nudix hydrolase, RP2p (NUDT19), was identified by proteomics analysis of mouse kidney peroxisomes [82]. This enzyme also functions as a CoA diphosphatase, with activity toward medium- and long-chain acyl-CoAs, branched-chain and bile acid-CoA esters, resulting in the production of 3',5'ADP and acyl-4'-phosphopantetheine. Therefore, NUDT7 and NUDT19 may hydrolyze similar substrates, however Nudt7 is mainly expressed in liver whereas Nudt19 is most strongly expressed in kidney, but also expressed in several other tissues. It has been shown that the peroxisomal membrane forms a permeability barrier for larger cofactors such as CoASH [83] and therefore the activity of nudix hydrolases would cleave CoASH into two smaller molecules (3',5'-ADP and 4'-phosphopantetheine) which could then exit the peroxisome. Currently there is no information as to possible functions of $3^{\prime}, 5^{\prime}$-ADP and 4'-phosphopantetheine in peroxisomes, but possibly 3',5'-ADP may exit peroxisomes via the adenine nucleotide transporter PMP34, (or Ant1 in yeast), which have been identified to be involved in the transport of adenine nucleotides across the peroxisomal membrane $[84,85]$. Similarly, 4'-phosphopantetheine may be recycled for CoA synthesis at the outer mitochondrial membrane, as the final two steps involve the transfer of an adenyl group from ATP to 4'-phosphopantetheine by phosphopantetheine adenylyltransferase to form dephospho-CoA, followed by phosphorylation by dephospho-CoA kinase to obtain CoASH (for review see [86]). ADP is also an extremely 
potent inhibitor of ACOT12 activity [48], which suggests a role for nucleotides in the regulation of acetate formation in peroxisomes. However, the surprising finding that the nudix hydrolases are more active on acyl-CoA's rather than with unesterified or oxidized CoASH raises questions regarding the in-vivo roles of these enzymes in peroxisomes, in particular in relation to the ACOT's. Hydrolysis of acyl-CoAs by ACOT enzymes will result in a free fatty acid, which can be re-esterified to CoASH or transported out of the peroxisome, together with a CoASH molecule that can be re-used in peroxisomes. In contrast, cleavage of acyl-CoAs by nudix hydrolases will result in catabolism of the CoASH molecule, resulting in a fatty acid with the 4'-phosphopantetheine attached (an acyl-4'-phosphopantetheine). As yet a possible function for this acyl-4'phosphopantetheine molecule is not known. A subject for future studies is obviously to determine whether ACOT enzymes are able to hydrolyze acyl-4'-phosphopantetheine molecules to release the free acid and 4'- phosphopantetheine.

\subsubsection{Involvement of ACOT4 and ACOT8 in regulation of peroxisomal $\beta$-oxidation of} dicarboxylic acids

Dicarboxylic acids were first detected in urine already in 1934 by Verkade and van der Lee [87]. In the 1980's it was established that succinate (a four carbon dicarboxylic acid) is present in urine in considerable amounts under normal conditions [88], in addition to longer chain dicarboxylic acids (DCA) like adipic acid $\left(\mathrm{C}_{6}-\mathrm{DCA}\right)$, suberic acid $\left(\mathrm{C}_{8}\right.$-DCA) and sebacic acid $\left(\mathrm{C}_{10}\right.$-DCA), which are increased in urine during conditions of high $\beta$ oxidation activity such as fasting, fat-feeding and diabetes [88-91]. Dicarboxylic acids 
are formed by omega oxidation of monocarboxylic fatty acids (which are not esterfied to CoASH). This occurs by an initial hydroxylation of the $\omega$-carbon, or the $\omega-1$ carbon, by microsomal CYP4A enzymes, followed by further oxidations by alcohol and aldehyde dehydrogenases, which finally results in formation of a dicarboxylic acid [92]. Under normal physiological conditions, $\omega$-oxidation is a minor pathway, accounting for about 5$10 \%$ of fatty acid oxidation, however during conditions such as starvation or diabetes, $\omega$ oxidation becomes more important [93]. There has been much debate as to whether $\beta$ oxidation of dicarboxylic fatty acids occurs in mitochondria [94] or peroxisomes [72, 9598]. However recent studies using human skin fibroblasts showed that the $\beta$-oxidation of C16 dicarboxylic acids occurs only in peroxisomes [99]. Dicarboxylic acids enter peroxisomes, likely as the CoA ester, and are then chain shortened by $\beta$-oxidation, involving the straight chain acyl-CoA oxidase, the D- and L-specific bifunctional proteins and SCPx $[99,100]$. Medium- and long-chain dicarboxylic acids are formed from $\omega$ oxidation as described above, whereas short chain dicarboxylic acids (such as adipic, suberic and sebacic acid) are formed from chain shortening of longer chain dicarboxylic acids by $\beta$-oxidation. The dicarboxylic acids oxidized in peroxisomes are believed to originate from mitochondrially produced monocarboxylic acids [91, 98, 101], but recently also very long-chain and long-chain monocarboxylic fatty acids have been shown to be omega-oxidized to dicarboxylic acids [102, 103]. In peroxisomes, the oxidation of $\mathrm{C} 12$ dicarboxylic acids results in chain shortening to adipic acid, suberic and sebacic acid [95]. Zellweger patients, who are deficient in peroxisomal $\beta$-oxidation, also excrete adipic acid, suberic and sebacic acid, however, they excrete increased amounts of suberic and sebacic acid in urine [104-106] suggesting there is a relative block in $\beta$ - 
oxidation oxidation of suberic to adipic acid in these patients. It has been proposed that peroxisomes oxidize dicarboxylic acids down to adipic acid, but it is unclear if this oxidation can proceed to succinic acid. Treatment of rats with adipic acid showed that this dicarboxylic acid was not oxidized but was excreted as adipic acid [90], which may be due to two factors, one being that the activiation of adipic acid to adipyl-CoA becomes rate-limiting as the dicarboxylyl-CoA synthetase does not appear to be active on short chain substrates, or secondly that the $\beta$-oxidation enzymes may not handle dicarboxylic acids of six carbons, and therefore the adipic acid is not $\beta$-oxidized [107].

Characterization of peroxisomal ACOT's identified two acyl-CoA thioesterases that show activity towards dicarboxylic acids, namely ACOT4 and ACOT8. In mouse, ACOT4 is a specific succinyl-CoA thioesterase, with some low activity also towards glutaryl-CoA [25]. Although the human ACOT4 enzyme has a much broader substrate specificity than the mouse ACOT4, the highest activity is found with succinyl-CoA [29]. ACOT4 is mainly expressed in kidney and liver in both mouse and human, which are the main organs of dicarboxylic acid formation. The identification of these succinyl-CoA thioesterases suggests that the oxidation of dicarboxylic acids may continue to succinate, by hydrolysis of succinyl-CoA to succinate, which can then be excreted from peroxisomes into urine. Alternatively, based on the discussion above that $\beta$-oxidation of dicarboxylic acids may not proceed beyond adipic acid, the existence of such specific succinyl-CoA thioesterases in peroxisomes strongly suggest that succinyl-CoA is formed in peroxisomes, possibly by a hitherto unidentified pathway. One possibility is that the succinate formed during peroxisomal $\alpha$-oxidation [108] may be activated to the CoA 
ester in peroxisomes, which may require hydrolysis for elimination. Succinyl-CoA is unlikely to be converted to a carnitine ester in peroxisomes, therefore elimination of succinyl-CoA would require the action of ACOT4. Interestingly, ACOT8 (the 'general' peroxisomal acyl-CoA thioesterase) can also hydrolyze dicarboxylyl-CoAs to the free acid and CoASH, but the specificity appears to complement the activity of ACOT4 (Fig 5) and mainly hydrolyzes longer chain dicarboxylic acids [25]. Given that ACOT8 is inhibited by CoASH, it is likely that the oxidation of dicarboxylic acids can proceed to produce shorter chain dicarboxylic acids during normal conditions. However, during conditions where $\beta$-oxidation rates are high and $\mathrm{CoASH}$ is sequestered for the thiolase reaction, such as during fasting, ACOT8 will be activated, thus producing longer chain dicarboxylic acids in peroxisomes. Taken together, these data suggest that ACOT4 and ACOT8 are involved in the hydrolysis of short-, medium- and long-chain dicarboxylylCoA esters, respectively, to release dicarboxylic acids for excretion in urine (for an overview see Fig. 4). It should be emphasized that a fraction of the dicarboxylic acids excreted in the urine in human is in fact conjugated to glycine, a reaction that may possibly be carried out by bile acid-CoA:amino acid $N$-acyltransferase (BAAT) or a mitochondrial/cytosolic acyltransferase.

\subsubsection{ACOT6 in regulation of methyl branched lipid oxidation}

Phytol is formed from chlorophyll in the gut of ruminant animals and phytol is therefore ingested in the diet from dairy products. As mammals cannot metabolize phytol directly, phytol is converted to phytanic acid in the intestine directly, or is taken up and converted 
to phytanic acid in the intestine or in other tissues. Phytanic acid $(3,7,11,15$ tetramethylhexadecanoic acid) is a 3-methyl branched fatty acid and therefore cannot undergo $\beta$-oxidation directly. Therefore, phytanic acid is first activated to phytanoyl-CoA and subsequently metabolized to pristanic acid by a process known as alpha-oxidation (for review see [108]). Mutations in one of the genes involved in this process, phytanoylCoA hydroxylase $(P H Y H)$, results in Refsum disease (for review on phytanic acid and human disease see [109]). This $\alpha$-oxidation process occurs in peroxisomes by a dedicated set of enzymes, although it has been disputed if the final enzymatic step by a fatty aldehyde dehydrogenase also occurs in peroxisomes [110]. Recently however, alternative splicing of the fatty aldehyde dehydrogenase was shown to result in a dual localization in the endoplasmic reticulum and peroxisomes, indicating that all enzymes required for $\alpha$ oxidation are indeed localized in peroxisomes [111]. The conversion of a 3-methyl branched fatty acid (phytanic acid) to a 2-methyl branched fatty acid (pristanic acid $(2,6,10,14$-tetramethylpentadecanoic acid)) results in a carboxylic acid that can then undergo $\beta$-oxidation. However, the $\beta$-oxidation of 2 -methyl branched substrates is further complicated by the stereo-specificity of the substrate. Only $2 \mathrm{~S}$ isomers of pristanic acid can undergo $\beta$-oxidation and therefore the $2 \mathrm{R}$ isomer needs to be converted to the $2 \mathrm{~S}$ isomer, in a reaction catalyzed by the enzyme alpha-methylacyl-CoA racemase (AMACR) $[112,113]$. As this enzyme contains both a mitochondrial targeting signal and a peroxisomal type 1 targeting signal, the protein localizes in both peroxisomes and mitochondria [114]. AMACR deficiency results in adult onset sensory motor neuronal and liver abnormalities $[115,116]$. The $2 \mathrm{~S}$ isomer of pristanoyl-CoA undergoes $\beta$ - 
oxidation in peroxisomes by the sequential reactions of branched chain acyl-CoA oxidase (ACOX3), the D-bifunctional protein and SCPX.

We recently identified an acyl-CoA thioesterase (ACOT6) that only hydrolyzes CoA esters of phytanic acid and pristanic acid, and can therefore function as an auxiliary enzyme in the metabolism of alpha-methyl branched fatty acids [27]. This enzyme has a $\mathrm{K}_{\mathrm{m}}$ of $\approx 24 \mu \mathrm{M}$ for pristanoyl-CoA, and is localized in peroxisomes. The specific activity of phytanoyl-CoA/pristanoyl-CoA thioesterase was very high in highly purified mouse liver peroxisomes, compared to the activity with myristoyl-CoA, and an anti-ACOT6 antibody immunoprecipitated essentially all of the phytanoyl/pristanoyl-CoA activity, but none of the myristoyl-CoA thioesterase activity, showing that ACOT6 is the main acylCoA thioesterase in peroxisomes that hydrolyzes these branched chain CoA esters [27]. Surprisingly, this mRNA is most strongly expressed in white adipose tissue, but it was shown to be strongly co-expressed with Acox3 in most tissues, which is the presumed rate-limiting enzyme involved in the $\beta$-oxidation of pristanoyl-CoA. White adipose tissue is the main organ involved in the storage of pristanic acid, and in rats, approx $10 \%$ of ingested pristanic acid is found in white adipose tissue and liver one week after treatment $[117,118]$. The identification of an ACOT specific for branched chain acyl-CoA esters in white adipose tissue suggested an unexpected role for ACOT6 in this tissue. As stated above, the $2 \mathrm{R}$ isomer of pristanoyl-CoA must be converted to the $2 \mathrm{~S}$ isomer before it can be $\beta$-oxidized. Expression analysis showed that Amacr mRNA levels are very low in white adipose tissue, suggesting that conversion of the $2 \mathrm{R}$-isomer to the $2 \mathrm{~S}$-isomer may be rate-limiting and thereby hamper $\beta$-oxidation of pristanic acid [27]. Strikingly, 
ACOT6 does not show stereo-specificity for the $2 \mathrm{R}$ and $2 \mathrm{~S}$ isomers and can therefore hydrolyze both isomers of pristanoyl-CoA. The current hypothesis is therefore that the $2 \mathrm{R}$ isomer would be hydrolyzed by ACOT6 in white adipose tissue, due to inadequate activity of AMACR, to release the free acid and $\mathrm{CoASH}$, and the $2 \mathrm{R}$ pristanic acid may exit the peroxisome to be re-activated to the CoA ester in the cytosol and esterified into triacylglycerols. Alternatively, the 2R-isomer could enter the circulation to be transported back to the liver where it can be racemized by the AMACR to the $2 \mathrm{~S}$ isomer, thus allowing its degradation by peroxisomal $\beta$-oxidation (Fig. 6). Pristanic acid undergoes three rounds of $\beta$-oxidaiton in peroxisomes, resulting in the production of 4,8 dimethylnonanoyl-CoA (DMN-CoA). This DMN-CoA can then be hydrolyzed to free DMN acid by ACOT8 or ACOT5 (the latter being most highly expressed in white adipose tissue), since both enzymes show appreciable activity towards DMN-CoA [26, 37]. However, it may be that ACOT8 is most significant in this hydrolysis as it has a $\mathrm{K}_{\mathrm{m}}$ of $5 \mu \mathrm{M}$ for this substrate. Alternatively, DMN can be esterified to carnitine by CROT (in liver, intestine and kidney), and transferred to mitochondria for further degradation to 2,6-dimethylheptanoyl-CoA [70].

\subsubsection{Acyl-CoA thioesterases and synthesis of polyunsaturated fatty acid}

Docosahexanoic acid (DHA) (C22:6n-3) is the major n-3 polyunsaturated fatty acid (PUFA) in adult mammalian brain and retina and is found in amino phospholipids of cell membranes. It is now well established that DHA formation involves a combined reaction sequence of desaturation and elongation with a final step of $\beta$-oxidaiton in peroxisomes, in which $\mathrm{C} 24: 6 n-3$ is $\beta$-oxidized to $\mathrm{C} 22: 6 n-3$ and $\mathrm{C} 24: 5 n-6$ oxidized to $\mathrm{C} 22: 5 n-6$ (for 
review see [119]). Fibroblasts from Zellweger patients cannot produce DHA [120, 121], confirming that the final step of DHA formation takes place in peroxisomes. The DHA is then incorporated into phospholipids in the endoplasmic reticulum after it's synthesis in peroxisomes. The enzymes involved in $\beta$-oxidation of $\mathrm{C} 24: 6 \mathrm{n}-3$ to $\mathrm{C} 22: 6 \mathrm{n}-3$ have been elucidated and involves the straight chain acyl-CoA oxidase (ACOX1), the Dbifunctional protein and both the 3-ketoacyl-CoA thiolase and SCPx [120]. Although, to date no specific acyl-CoA thioesterase enzyme has been identified in the metabolism of DHA in peroxisomes, acyl-CoA thioesterase activity towards C22:6n-3 and C24:6n-3 has been identified in purified mouse kidney peroxisomes and it was suggested that DHA could be transported to the endoplasmic reticulum as the free acid [122]. Given the wide substrate specificity of ACOT8 and its ubiquitous tissue expression, it is likely that this enzyme can hydrolyze DHA to the free acid in peroxisomes, and work is currently underway in our laboratory to elucidate which ACOT is involved in this process.

\section{The acyltransferases involved in conjugation (amidation) of bile acids and fatty acids in peroxisomes}

\subsection{The acyl-CoA:amino acid N-acyltransferase gene cluster}

There is a further gene cluster related to the Type-I Acots (discussed in Section 2.1.1), which contains three distinct genes localized on chromosome 4 B3 in mouse (Fig. 7). These genes are named bile acid-CoA:amino acid $N$-acyltransferase (BAAT) and acylCoA:amino acid $N$-acyltransferase 1 and 2 (ACNAT1 and 2), which show approximately 
$40 \%$ sequence identity to the ACOT 3, 4, 5 and 6 at protein level. The Baat and the Acnats show about 55\% sequence identity to each other, whereas Acnat1 and Acnat 2 show $96 \%$ sequence identity to eachother. All three of these gene products appear to be localized in peroxisomes, although there is still some confusion regarding the cellular localization of BAAT (see below). The corresponding gene "cluster" in humans only contain two genes, one coding for $B A A T$, and an apparent $A C N A T$ pseudogene, which contains in-frame stop codons and therefore would not code for a functional protein, although it contains a peroxsomal targeting signal of -SKL (Fig. 7).

\subsubsection{Peroxisomes contain a bile-acid conjugating enzyme catalyzing the terminal step in bile acid synthesis.}

It is well established that the conjugation (or amidation) of bile acids occurs in peroxisomes, resulting in the production of bile salts that are excreted into bile and stored in the gallbladder. This final step in the conversion of cholesterol to bile acids involves one round of $\beta$-oxidation of the side-chain of the $\mathrm{C} 27$ bile-acid precursors trihydroxycoprostanoyl-CoA and dihydroxycoprostanoyl-CoA to chenodeoxycholoylCoA and choloyl-CoA (the C24 bile acids) [123-127]. These C24 bile acids are then conjugated (or amidated) to glycine or taurine (depending on the species) by the enzyme bile acid-CoA:amino acid $N$-acyltransferase (BAAT) [128-132]. The intracellular localization of BAAT has been reported to be both cytosolic and peroxisomal. In the 1960 's, bile acid conjugation activity was reported in the lysosomal fraction (or possibly the peroxisomal fraction) of human liver [133] and was later identified in the microsomal 
and peroxisomal fractions of rat liver homogenates [134]. Further studies showed that BAAT activity is distributed in microsomes, cytosol or peroxisomes in rat, mouse and human $[130,134-139]$. In view of the data showing BAAT activity in cytosol/microsomes and peroxisomes, it has been hypothesized that two pathways for amidation of bile acids exist, one pathway in peroxisomes for the amidation of the denovo synthesized primary bile acids, cholic acid and chenodeoxycholic acid, and a second pathway in the cytosol for the re-amidation of deconjugated primary and secondary bile acids recycled back to the liver via the enterohepatic circulation. The human very long-chain acyl-CoA synthetase homolog 2 (VLCS), also known as BACS (bile acid-CoA synthetase), was shown to activate the primary bile acids cholate [140] and chenodeoxycholate, and also the secondary bile acids deoxycholate and lithocholate [141] in the cytosol, also suggesting two pathways of bile acid metabolism, with the cytosolic pathway being responsible for reactivation/reconjugation of recycled bile acids. Recently, recombinantly expressed human BAAT has also been shown to conjugate fatty acids (mainly long-chain acyl-CoAs) to glycine and taurine [131] (Fig. 8). Mouse, rat and human BAAT proteins show approx $70 \%$ sequence identity to each other, which all contain a carboxyterminal serine, glutamine, leucine sequence (-SQL). This tripeptide is a variant of the consensus peroxisomal targeting signal of serine, lysine, leucine (-SKL), known to target proteins to peroxisomes [142]. Studies on the cellular localization of BAAT using green fluorescent fusion proteins showed that this fusion protein was entirely cytosolic in human skin fibroblasts [131], which was confirmed in other studies [143]. However, in rat and human primary hepatocytes, BAAT was localized in peroxisomes [143], suggesting that targeting of non-consensus PTS1-containing proteins 
may be more efficient in liver cells than for example in fibroblasts. In this study by Pellicoro, co-transfection of human BAAT and a peroxisomal marker DSRed-SKL in rat primary hepatocytes, resulted in a cytosolic localization of BAAT, suggesting that the peroxisomal import machinery becomes saturated with DSRed-SKL and therefore targeting of BAAT, which contains a non-consensus targeting signal of -SQL, is inefficient. As a result, in liver where BAAT is highly expressed, the protein is likely to be mainly peroxisomal and involved in the amidation of de-novo synthesized bile acids as discussed in a recent review on peroxisomes and bile acid biosynthesis [144]. However, it still cannot be excluded at this stage that BAAT has a dual localization in cytosol and peroxisomes, and that this dual localization may be affected by pharmacological treatment [135]. Thus, the mechanism for targeting of BAAT to peroxisomes is still not fully understood and needs further consideration.

The catalytic triad of BAAT has been elucidated and involves a cysteine, aspartic acid and histidine, similar to the Type I ACOT enzymes, however the ACOTs contain an active site serine in place of the cysteine in BAAT $[131,145]$. Interestingly, the ACNATs also contain an active site serine, however this serine is localized in a SerXaaSerXaaGly motif and not in a GlyXaaSerXaaGly motif common to the ACOTs [146]. A mutation in the BAAT protein (and tight junction protein 2) in an Amish population resulted in familial hypercholanemia, which is characterized by elevated serum bile acid concentrations, itching and fat malabsorption [147]. 
4.1.2. Peroxisomes contain two putative acyl-CoA:amino acid $N$-acyltransferases that conjugate fatty acids and possibly other carboxylic acids

Two further genes related to Baat have been identified in mouse (Fig. 7), however as stated earlier, the ACNAT gene in human is a pseudogene. These mouse genes encode two novel acyl-CoA:amino acid $N$-acyltransferases (ACNAT1 and ACNAT2) and one of these enzymes, ACNAT1, was recently characterized [146]. These two ACNAT proteins show approx 55\% sequence identity to BAAT, with $95 \%$ sequence identity to each other. ACNAT1 and ACNAT2 both contain a consensus peroxisomal targeting signal of -SKL at the carboxyterminal end, which localizes the proteins to peroxisomes [146] (and Reilly et al, unpublished results). Acnatl mRNA is mainly expressed in liver and kidney in mouse, and characterization of recombinant ACNAT1 protein identified it as a peroxisomal acyltransferase involved in conjugation of mainly very long-chain and longchain fatty acids $\left(\mathrm{C}_{16}-\mathrm{C}_{24}\right)$ to taurine, with some very low activity with bile acids [146]. The identification of this taurine conjugating activity in peroxisomes suggests a possible novel pathway for metabolism/excretion of long-chain fatty acids as taurine conjugates (Fig. 8). Interestingly, the group of Cravatt recently identified taurine-conjugated fatty acids ( $\mathrm{N}$-acyltaurines) as a novel class of endogenous signaling lipids. These $\mathrm{N}$ acyltaurines (NATs) were first detected by global metabolic profiling in the fatty acid amide hydrolase (FAAH) knockout mouse model in brain, spinal cord, testes and liver $[148,149]$. The FAAH is an integral membrane protein that degrades endogenous signaling lipids [150], thereby regulating in-vivo levels of signaling molecules. Notably, these taurine conjugates were mainly of $\mathrm{C}_{16}-\mathrm{C}_{26}$ in chain length, similar to the chain 
length specificity for ACNAT1. In wild-type FAAH animals, these NATs were detected at approx 20-50 pmol/g tissue, however, in the FAAH knockout mouse model, levels of these NATs rose to nmol/g levels. Taurine conjugates of unsaturated long-chain fatty acids such as arachidonyltaurine (C20:4 taurine) were also detected in liver and kidney at concentrations of $20 \mathrm{pmol} / \mathrm{g}$ in liver and $157 \mathrm{pmol} / \mathrm{g}$ in kidney, respectively. Interestingly, arachidonyltaurine was shown to activate transient receptor potential (TRP) channels, TRPV1 and TRPV4, which are expressed in kidney, with an $\mathrm{EC}_{50}$ value of 28 $\mu \mathrm{M}$ and $21 \mu \mathrm{M}$ respectively, suggesting a role for taurine conjugated fatty acids in cell signalling [151]. However, arachidonoyl-CoA is a poor substrate for ACNAT1, suggesting that there is one or more acyltransferases that can conjugate this fatty acid to taurine, possibly ACNAT2 for which there is as yet no report with respect to it's substrate specificity. The TRPV1 and TRPV4 calcium channels are proposed to play roles in regulation of blood pressure and osmotic sensation [152], however further physiological studies are warranted to elucidate the role of ACNAT1 (or ACNAT2) in these processes.

The identification of $\mathrm{N}$-acyltaurines (especially saturated $\mathrm{N}$-acyltaurines) in brain raises the question if these molecules are formed in-situ in brain or could be synthesized by ACNAT1 in liver and kidney, and be transported to the brain via the bloodstream. We have detected long chain NATs in serum, which under normal conditions are detected at low levels, however during prolonged fasting, and in particular in PPAR $\alpha$-knockout mice, strongly elevated levels can be detected (Reilly et al, unpublished observation), suggesting that amidation of fatty acids may provide an important excretory pathway for fatty acids in bile or urine under some conditions. NATs are also substrates for and 
FAAH can hydrolyze NATs back to the free acid plus taurine, thus regulating in-vivo levels of NATs [149].

Peroxisomes are also associated with the metabolism of certain xenobiotics [49] and the $\beta$-oxidation of very long chain acyl-CoAs, prostaglandins, and bile acids, all of which are substrates for taurine (or glycine) conjugation. Searches in the literature showed that taurine and/or glycine conjugation of a number of physiological substrates and xenobiotic compounds, including a number of pharmaceutical drugs, involves partial $\beta$-oxidation followed by conjugation to taurine or glycine, and subsequent excretion into urine or bile. However, there are large species differences in the taurine conjugates identified, with taurine conjugates of cerivastatin metabolites identified in dog [153], taurine conjugated prostaglandins identified in rat [154] and an unusual taurine conjugate of ganglioside GM2 identified in Tay-Sachs brain [155]. These aspects should be interesting to explore in future studies in relation to species-specific expression and substrate specificities of these acyltransferases that may also have very important functions in drug metabolism.

The substrate specificity of ACNAT2 has not yet been characterized, but as this enzyme is also peroxisomal and shows $95 \%$ sequence identity to ACNAT1, we speculate that this enzyme also functions as a taurine conjugator in peroxisomes, with the likely substrates being unsaturated fatty acids and possibly xenobiotics. As stated above, taurine conjugates of unsaturated fatty acids have been identified in brain, liver and kidney [148, 151], however ACNAT1 only conjugates saturated fatty acids. 


\section{Regulation of peroxisomal acyl-CoA thioesterases and acyltransferases}

\subsection{Regulation of Acots and acyltransferases in peroxisomes}

Currently, there is little information available on regulation of peroxisomal ACOT enzymes, however all are targets of the PPAR $\alpha$. Fibrates belong to a group of compounds that act as ligands for the PPAR $\alpha$ and treatment of rodents with these compounds results in an increase in the number and size of peroxisomes and in an increase in peroxisomal $\beta$ oxidation [4]. The enzymes of the straight chain $\beta$-oxidation pathway are strongly upregulated via fibrate treatment, whereas the enzymes in branched chain oxidation are unaltered by such treatment [156]. In line with an increase in peroxisomal $\beta$-oxidation, Acot3, 4, 5 and 6 are all upregulated by fibrate treatment at both protein and mRNA levels [25-27]. This upregulation is dependent on the PPAR $\alpha$, as upregulation was of Acot3, 4, 5 and 6 ablated in the PPAR $\alpha$ knockout mouse model. Similarly, Acot 8 is also upregulated by fibrates in a PPAR $\alpha$-dependent manner [37]. During fasting conditions, also known to result in increased PPAR $\alpha$ activation and upregulation of peroxisomal $\beta$ oxidation, only $A \cot 3, A \cot 4, A \cot 5$ and $A \cot 8$ are upregulated at mRNA level [25, 26, 37]. At present there are no data available on quantitative changes in Acot12 mRNA in response to fibrate treatment, but ACOT12 activity is increased in the peroxisomal fraction (per gram of liver tissue) and in the cytosolic fraction, suggesting that Acot12 expression is indeed increased in response to fibrates [46]. Recently, a list of genes compiled from array data of PPAR $\alpha$ wild-type and PPAR $\alpha$-null mice, showed that Acot12 is regulated by fasting and $\mathrm{Wy}-14,643$ in mouse liver [157]. Ebisuno et al also 
showed an increase of ACOT12 activity in early diabetic conditions, and by cholesterol and clofibrate feeding, but no change was observed in chronic diabetes [158]. In summary, the findings that the expression of all peroxisomal ACOT's is increased in response to $\operatorname{PPAR} \alpha$ activation suggests that these enzymes do promote $\beta$-oxidation in peroxisomes. Furthermore, Acot3 was shown to be upregulated 13-fold in mouse liver following a chemical knockout of the pantothenate kinase (PanK), the rate limiting enzyme in CoA biosynthesis [159]. Interestingly, the cytosolic and mitochondrial Acots (Acot1 and Acot 2 respectively) were also upregulated over 40 -fold at mRNA level in the PanK knockout, suggesting that all the thioesterases are indeed important enzymes in regulating hepatic CoASH levels. The mouse ACOT3 was also recently identified in a proteomic study of mitochondrial phosphoproteins, as a phosphorylated protein, with phosphorylation on serine 67 of ACOT3 (serine 56 in ACOT4, 5 and 6) [160]. Interestingly, this serine is conserved in all mouse peroxisomal ACOTs but not in human ACOT4, suggesting a possible species-specific phosphorylation of mouse peroxisomal ACOT's.

As Acnat1 and Acnat 2 have been identified very recently, there is currently little information on their regulation, but Acnatl does not appear to be regulated by fibrate treatment, fasting or bile acid treatment (unpublished observation). In contrast, Acnat2 is strongly upregulated by treatment of mice with fibrates and statins (Reilly et al unpublished results). In mouse, Baat mRNA and activity has been shown to be downregulated by fibrate treatment $[135,139]$, but in rat treatment with clofibrate results in an increased activity of BAAT in peroxisomes in male mice, but the activity is 
decreased in female mice [135]. Baat mRNA is upregulated by cholestyramine (a bile acid binding resin) treatment in mouse liver [139], whereas in rat, BAAT activity is unchanged by cholestyramine treatment [135], showing a distinct species difference. Baat is regulated by the farnesoid $\mathrm{X}$ receptor (FXR) in the rat via an inverted repeat 1 (IR-1) element located in the first intron of the gene and Baat mRNA levels were increased in rats following treatment with a synthetic FXR ligand [161]. Baat expression is also regulated by the hepatocyte nuclear factor 4 alpha $(\mathrm{HNF}-4 \alpha)$ via a response element in the promoter and expression of the Baat mRNA is not detectable in the HNF- $4 \alpha$ knockout mouse, resulting in markedly elevated levels of unconjugated bile acids in gallbladder in this knockout model [162]. Recently Baat expression was shown to be reduced in sepsis in rat via the retinoid $X$ receptor-alpha [163]. Taken together, the profound regulation of the ACOTs and acyltransferase genes by various nuclear receptors support the notion that these enzymes have important regulatory functions in different metabolic pathways.

\section{Concluding remarks and perspectives}

The identification of a family of acyl-CoA thioesterases/acyltransferases in peroxisomes has led to the identification of novel metabolic pathways for fatty acids in this organelle. It is hoped that future studies using knockout mouse models and knockdown studies will help to identify precise roles for these enzymes in peroxisomal lipid metabolism, which could lead to identification of patients with new previously uncharacterized peroxisomal disorders. 


\section{Acknowledgements.}

This study was supported by the Swedish Research Council, the FP6 European Union Project "Peroxisome” (LSHG-CT-2004-512018), AFA sjukförsäkrings jubileumsstiftelse, Åke Wibergs stiftelse, Lars Hiertas Minne, Fredrik and Ingrid Thurings Stiftelse, Ruth and Richard Julins Stiftelse, and Stiftelsen Professor Nanna Svartz fond. 


\section{References}

1. De Duve C. Functions of microbodies (peroxisomes). J. Cell Biol. 1965;27:25A26A.

2. Goldfischer S, Moore CL, Johnson AB, Spiro AJ, Valsamis MP, Wisniewski HK, Ritch RH, Norton WT, Rapin I, Gartner LM. Peroxisomal and mitochondrial defects in the cerebro-hepato-renal syndrome. Science 1973;182:62-64.

3. Hashimoto T. Peroxisomal beta-oxidation enzymes. Neurochem. Res. 1999;24:551-563.

4. Reddy JK, Mannaerts GP. Peroxisomal lipid metabolism. Annu. Rev. Nutr. 1994;14:343-370.

5. Hiltunen JK, Yong-Mei Q. $\beta$-oxidation - strategies for the metabolism of a wide variety of acyl-CoA esters. Biochim. Biophys. Acta 2000;1484:117-128.

6. Wanders RJA, Waterham HR. Biochemistry of mammalian peroxisomes revisited. Annu. Rev. Biochem. 2006;75:295-332.

7. Wanders RJA. Metabolic and molecular basis of peroxisomal disorders: A review. Am. J. Hum. Genet. 2004;126A:355-375.

8. Platta HW, Erdmann R. Peroxisomal dynamics. Trends Cell Biol. 2007;17:474484.

9. Weller S, Gould SJ, Valle D. Peroxisome biogenesis disorders. Annu. Rev. Genomics Hum. Genet. 2003;4:165-211.

10. Schrader M, Fahimi HD. The peroxisome: still a mysterious organelle. Histochem. Cell. Biol. 2008; epub 15 Feb 2008.

11. Gould SJ, Collins CS. Opinion: peroxisomal-protein import: is it really that complex? Nat. Rev. Mol. Cell Biol. 2002;3:382-389.

12. Gergely J, Hele P, Ramakrishnan CV. Succinyl and acetyl coenzyme A deacylases. J. Biol. Chem. 1952:323-335.

13. Hunt MC, Alexson SEH. The role acyl-CoA thioesterases play in mediating intracellular lipid metabolism. Prog. Lipid Res. 2002;41:99-130.

14. Hunt MC, Yamada J, Maltais LJ, Wright MW, Podesta EJ, Alexson SEH. A revised nomenclature for mammalian acyl-CoA thioesterases/hydrolases. J. Lipid Res. 2005;46:2029-2032.

15. Berge RK, Flatmark T, Osmundsen H. Enhancement of long-chain acyl-CoA hydrolase activity in peroxisomes and mitochondria of rat liver by peroxisomal proliferators. Eur. J. Biochem. 1984;141:637-644.

16. Berge RK, Skrede S, Farstad M. Effects of clofibrate on the intracellular localization of palmitoyl-CoA hydrolase and palmitoyl-L-carnitine hydrolase in rat liver. FEBS Lett. 1981;124:43-47.

17. Svensson LT, Alexson SEH, Hiltunen JK. Very long chain and long chain acylCoA thioesterases in rat liver mitochondria. Identification, purification, characterization, and induction by peroxisome proliferators. J. Biol. Chem. 1995;270:12177-12183.

18. Miyazawa S, Furuta S, Hashimoto T. Induction of a novel long-chain acyl-CoA hydrolase in rat liver by administration of peroxisome proliferators. Eur. J. Biochem. 1981;117:425-430.

19. Mandard S, Müller M, Kersten S. Peroxisome proliferator-activated receptor $\alpha$ target genes. Cell. Mol. Life Sci. 2004;61:393-416. 
20. Wilcke M, Alexson SEH. Characterization of acyl-CoA thioesterase activity in isolated rat liver peroxisomes. Eur. J. Biochem. 1994;222:803-811.

21. Alexson SEH, Osmundsen H, Berge RK. The presence of acyl-CoA hydrolase in rat brown-adipose-tissue peroxisomes. Biochem. J. 1989;262:41-46.

22. Svensson LT, Wilcke M, Alexson SEH. Peroxisome proliferators differentially regulate long-chain acyl-CoA thioesterases in rat liver. Eur. J. Biochem. 1995;230:813820.

23. Yamada J, Matsumoto I, Furihata T, Sakuma M, Suga T. Purification and properties of long-chain acyl-CoA hydrolases from the liver cytosol of rats treated with peroxisome proliferator. Arch. Biochem. Biophys. 1994;308:118-125.

24. Hunt MC, Nousiainen SEB, Huttunen MK, Orii K, Svensson LT, Alexson SEH. Peroxisome proliferator-induced long chain acyl-CoA thioesterases comprise a highly conserved novel multi-gene family involved in lipid metabolism. J. Biol. Chem. 1999;274:34317-34326.

25. Westin MAK, Hunt MC, Alexson SEH. The identification of a succinyl-CoA thioesterase suggests a novel pathway for succinate production in peroxisomes. J. Biol. Chem. 2005;280:38125-38132.

26. Westin MAK, Alexson SEH, Hunt MC. Molecular cloning and characterization of two mouse peroxisome proliferator-activated receptor alpha (PPAR $\alpha$ )-regulated peroxisomal acyl-CoA thioesterases. J. Biol. Chem. 2004;279:21841-21848.

27. Westin MAK, Hunt MC, Alexson SEH. Peroxisomes contain a specific phytanoyl-CoA/pristanoyl-CoA thioesterae acting as a novel auxiliary enzyme in alphaand beta-oxidation of methyl-branched fatty acids in mouse. J. Biol. Chem. 2007;282:26707-26716.

28. Westin MAK, Hunt MC, Alexson SEH. Short- and medium-chain carnitine acyltransferases and acyl-CoA thioesterases in mouse provide complementary systems for transport of beta-oxidation products out of peroxisomes. Cell. Mol. Life Sci. 2008; epub 12 Feb 2008.

29. Hunt MC, Rautanen A, Westin MAK, Svensson LT, Alexson SEH. Analysis of mouse and human acyl-CoA thioesterase (ACOT) gene clusters shows that convergent functional evolution results in a reduced number of peroxisomal ACOTs. FASEB J. 2006;20:1855-1864.

30. Huhtinen K, O'Byrne J, Lindquist PJG, Contreras JA, Alexson SEH. The peroxisome proliferator-induced cytosolic type I acyl-CoA thioesterase (CTE-I) is a serine-histidine-aspartic acid alpha/beta hydrolase. J. Biol. Chem. 2002;277:3424-3432.

31. Watanabe H, Shiratori T, Shoji H, Miyatake S, Okazaki Y, Ikuta K, Sato T, Saito T. A novel acyl-CoA thioesterase enhances its enzymatic activity by direct binding with HIV Nef. Biochem. Biophys. Res. Commun. 1997;238:234-239.

32. Liu LX, Margottin F, Le Gall S, Schwartz O, Selig L, Benarous R, Benichou S. Binding of HIV-1 Nef to a novel thioesterase enzyme correlates with Nef-mediated CD4 down-regulation. J. Biol. Chem. 1997;272:13779-13785.

33. Cohen GB, Rangan VS, Chen BK, Smith S, Baltimore D. The human thioesterase II protein binds to a site on HIV-1 Nef critical for CD4 down-regulation. J. Biol. Chem. 2000;275:23097-23105. 
34. Jones JM, Nau K, Geraghty MT, Erdmann R, Gould SJ. Identification of peroxisomal acyl-CoA thioesterases in yeast and human. J. Biol. Chem. 1999;274:92169223.

35. Maeda I, Delessert S, Hasegawa S, Seto Y, Zuber S, Poirier Y. The peroxisomal acyl-CoA thioesterase Pte1p from Saccharomyces cerevisiae is required for efficient degradation of short straight chain and branched chain fatty acids. J. Biol. Chem. 2006;281:11729-11735.

36. Tilton GB, Shockey JM, Browse J. Biochemical and Molecular Characterization of $\mathrm{ACH} 2$, an Acyl-CoA thioesterase from Arabidopsis thaliana. J. Biol. Chem. 2003;279:7487-7494.

37. Hunt MC, Solaas K, Kase BF, Alexson SEH. Characterization of an acyl-CoA thioesterase that functions as a major regulator of peroxisomal lipid metabolism. J. Biol. Chem. 2002;277:1128-1138.

38. Ofman R, el Mrabet L, Dacremont G, Spijer D, Wanders RJA. Demonstration of dimethylnonanoyl-CoA thioesterase activity in rat liver peroxisomes followed by purification and molecular cloning of the thioesterase involved. Biochem. Biophys. Res. Comm. 2002;290:629-634.

39. Ishizuka M, Toyama Y, Watanabe H, Fujiki Y, Takeuchi A, Yamasaki S, Yuasa S, Miyazaki M, Nakajima N, Taki S, Saito T. Overexpression of human acyl-CoA thioesterase upregulates peroxisome biogenesis. Experimental Cell Research 2004;297:127-141.

40. Li J, Derewenda U, Dauter Z, Smith S, Derewenda ZS. Crystal structure of the Escherichia coli thioesterase II, a homolog of the human Nef binding enzyme. Nat. Struct. Biol. 2000;7:555-559.

41. Zhuang Z, Song F, Zhao H, Li L, Cao J, Eisenstein E, Herzberg O, DunawayMariano D. Divergence of function in the hot dog fold enzyme superfamily: The bacterial thioesterase YciA. Biochemistry 2008; epub 2 february 2008.

42. Prass RL, Isohashi F, Utter MF. Purification and characterization of an extramitochondrial acetyl coenzyme A hydrolase from rat liver. J. Biol. Chem. 1980;255:5215-5223.

43. Suematsu N, Okamoto K, Shibata K, Nakanishi Y, Isohashi F. Molecular cloning and functional expression of rat liver cytosolic acetyl-CoA hydrolase. Eur. J. Biochem. 2001;268:2700-2709.

44. Suematsu N, Okamoto K, Isohashi F. Mouse cytosolic acetyl-CoA hydrolase, a novel candidate for a key enzyme involved in fat metabolism: cDNA cloning, sequencing and functional expression. Acta Biochim. Pol. 2002;49:937-945.

45. Suematsu N, Isohashi F. Molecular cloning and functional expression of human cytosolic acetyl-CoA hydrolase. Acta Biochim. Pol. 2006;53:553-561.

46. Nakanishi Y, Okamoto K, Isohashi F. Subcellular distribution of ATP-stimulated and ADP-inhibited acetyl-CoA hydrolase in livers from control and clofibrate-treated rats: comparison of the cytosolic and peroxisomal enzyme. J. Biochem. (Tokyo) 1994;115:328-332.

47. Wiese S, Gronemeyer T, Ofman R, Kunze M, Grou CP, Almeida JA, Eisenacher M, Stephan C, Hayen H, Schollenberger L, Korosec T, Waterham HR, Schliebs W, Erdmann R, Berger J, Meyer HE, Just W, Azevedo JE, Wanders RJA, Warscheid B. 
Proteomic characterization of mouse kidney peroxisomes by tandem mass spectrometry and protein correlation profiling. Mol. Cell. Proteomics 2007; epub 2 september 2007.

48. Söling H-D, Rescher C. On the regulation of cold-labile cytosolic and of mitochondrial acetyl-CoA hydrolase in rat liver. Eur. J. Biochem. 1985;147:111-117.

49. Suga T. Drug metabolism in peroxisomes: Involvement of peroxisomal betaoxidation system in the oxidative chain-shortening of xenobiotic acyl compounds. Drug Metab. Pharmacokinet. 2003;18:155-162.

50. Watkins PA. Very-long-chain acyl-CoA synthetases. J. Biol. Chem. 2008;283:1773-1777.

51. Kemp S, Wanders RJA. X-linked adrenoleukodystrophy: Very long-chain fatty acid metabolism, ABC half-transporters and the complicated route to treatment. Mol. Genet. Metab. 2007;90:268-276.

52. Mosser J, Douar AM, Sarde CO, Kioschis P, Feil R, Moser H, Poustka AM, Mandel JL, Aubourg P. Putative X-linked adrenoleukodystrophy gene shares unexpected homology with ABC transporters. Nature 1993;361:726-730.

53. Imanaka T, Aihara K, Takano T, Yamashita A, Sato R, Suzuki Y, Yokota S, Osumi T. Characterization of the $70-\mathrm{kDa}$ peroxisomal membrane protein, an ATP binding cassette transporter. J. Biol. Chem. 1999;274:11968-11976.

54. Visser WF, van Roermund CWT, Ijlst L, Waterham HR, Wanders RJA. Metabolite transport acoss the peroxisomal membrane. Biochem. J. 2007;401:365-375.

55. Osumi T, Ozasa H, Hashimoto T. Molecular cloning of cDNA for rat acyl-CoA oxidase. J. Biol. Chem. 1984;259:2031-2034.

56. Schepers L, Van Veldhoven PP, Casteels M, Eyssen HJ, Mannaerts GP. Presence of three acyl-CoA oxidases in rat liver peroxisomes. An inducible fatty acyl-CoA oxidase, a noninducible fatty acyl-CoA oxidase, and a noninducible trihydroxycoprostanoyl-CoA oxidase. J. Biol. Chem. 1990;265:5242-5246.

57. Nohammer C, El-Shabrawi Y, Schauer S, Hiden M, Berger J, Forss-Petter S, Winter E, Eferl R, Zechner R, G. H. cDNA cloning and analysis of tissue-specific expression of mouse peroxisomal straight-chain acyl-CoA oxidase. Eur. J. Biochem. 2000;267:1254-1260.

58. Baumgart E, Vanhooren JC, Fransen M, Marynen P, Puype M, Vanderkerckhove J, Leunissen JA, Fahimi HD, Mannaerts GP, Van Veldhoven PP. Molecular characterization of the human peroxisomal branched-chain acyl-CoA oxidase: cDNA cloning, chromosomal assignment, tissue distribution, and evidence for the absence of the protein in Zellweger syndrome. Proc. Natl. Acad. Sci. U.S.A. 1996;93:13748-13753.

59. Aoyama T, Tsushima K, Souri M, Kamijo T, Suzuki Y, Shimozawa N, Orii T, Hashimoto T. Molecular cloning and functional expression of a human peroxisomal acylcoenzyme A oxidase. Biochem. Biophys. Res. Commun. 1994;198:1113-1118.

60. Jiang LL, Miyazawa S, Hashimoto T. Purification and properties of rat D-3hydroxyacyl-CoA dehydratase: D-3-hydroxyacyl-CoA dehydratase/D-3-hydroxyacylCoA dehydrogenase bifunctional protein. J. Biochem. 1996;120:633-641.

61. Qin YM, Poutanen MH, Helander HM, Kvist AP, Silvari KM, Schmitz W, Conzelmann E, Hellman U, Hiltunen JK. Peroxisomal multifunctional enzyme of betaoxidation metabolizing D-3-hydroxyacyl-CoA esters in rat liver: molecular cloning, expression and characterization. Biochem. J. 1997;321:21-28. 
62. Palosaari PM, Hiltunen JK. Peroxisomal bifunctional protein from rat liver is a trifunctional enzyme possessing 2-enoyl-CoA hydratase, 3-hydroxyacyl-CoA dehydrogenase, and delta 3, delta 2-enoyl-CoA isomerase activities. J. Biol. Chem. 1990;265:2446-2449.

63. Wanders RJA, Denis S, Wouters F, Wirtz KWA, Seedorf U. Sterol carrier protein $\mathrm{X}(\mathrm{SCPx})$ is a peroxisomal branched-chain $\beta$-ketothiolase specifically reacting with 3oxo-pristanoyl-CoA: a new, unique role for SCPx in branched-chain fatty acid metabolism in peroxisomes. Biochem. Biophys. Res. Comm. 1997;236:565-569.

64. Seedorf U, Brysch P, Engel T, Schrage K, Assmann G. Sterol carrier protein X is peroxisomal 3-oxoacyl coenzyme A thiolase with intrinsic sterol carrier and lipid transfer activity. J. Biol. Chem. 1994;269:21277-21283.

65. Antonenkov VD, Van Veldhoven PP, Waelkens E, Mannaerts GP. Substrate specificities of 3-oxoacyl-CoA thiolase A and sterol carrier protein 2/3-oxoacyl-CoA thiolase purified from normal rat liver peroxisomes. Sterol carrier protein 2/3-oxoacylCoA thiolase is involved in the metabolism of 2-methyl-branched fatty acids and bile acid intermediates. J. Biol. Chem. 1997;272:26023-26031.

66. Seedorf U, Ellinghaus P, Roch Nofer J. Sterol carrier protein-2. Biochim. Biophys. Acta 2000;1486:45-54.

67. Antonenkov VD, Sormunen RT, Ohlmeier S, Amery L, Fransen M, Mannaerts GP, Hiltunen JK. Localization of a portion of the liver isoform of fatty-acid-binding protein (L-FABP) to peroxisomes. Biochem. J. 2006;394:475-484.

68. Markwell MAK, McGroarty EJ, Bieber LL, Tolbert NE. The subcellular distribution of carnitine acyltransferases in mammalian liver and kidney. J. Biol. Chem. 1973;248:3426-3432.

69. Markwell MAK, Bieber LL, Tolbert NE. Differential increase of hepatic peroxisomal, mitochondrial and microsomal carnitine acyltransferases in clofibrate-fed rats Biochem. Pharm. 1977;26:1697-1702.

70. Ferdinandusse S, Mulders J, IJlst L, Denis S, Dacremont G, Waterham HR, Wanders RJA. Molecular cloning and expression of human carnitine octanoyltransferase: evidence for its role in the peroxisomal $\beta$-oxidation of branched-chain fatty acids. Biochem. Biophys. Res. Commun. 1999;263:213-218.

71. Farrell SO, Fiol CJ, Reddy JK, Bieber LL. Properties of purified carnitine acyltransferases of mouse liver peroxisomes. J. Biol. Chem. 1984;259:13089-13095.

72. Leighton F, Bergseth S, Rørtveit T, Christiansen EN, Bremer J. Free acetate production by rat hepatocytes during peroxisomal fatty acid and dicarboxylic acid oxidation. J. Biol. Chem. 1989;264:10347-10350.

73. Bian F, Kasumov T, Thomas KR, Jobbins KA, David F, Minkler PE, Hoppel CL, Brunengraber $\mathrm{H}$. Peroxisomal and mitochondrial oxidation of fatty acids in the heart, assessed from the 13C labeling of malonyl-CoA and the acetyl moiety of citrate. J. Biol. Chem. 2005;280:9265-9271.

74. Wanders RJA, Komen JC. Peroxisomes, Refsum's disease and the alpha- and omega-oxidation of phytanic acid. Biochem. Soc. Trans. 2007;35:865-869.

75. Lazarow PB. Rat liver peroxisomes catalyze the beta oxidation of fatty acids. J. Biol. Chem. 1978;253:1522-1528.

76. Horie S, Isobe M, Suga T. Changes in CoA pools in hepatic peroxisomes of the rat under various conditions. J. Biochem. 1986;99:1345-1352. 
77. Van Broekhoven A, Peeters M-C, Debeer LJ, Mannaerts GP. Subcellular distribution of coenzyme A: Evidence for a separate coenzyme a pool in peroxisomes. Biochem. Biophys. Res. Commun. 1981;100:305-312.

78. Van Veldhoven PP, Mannaerts GP. Coenzyme A in purified peroxisomes is not freely soluble in the matrix but firmly bound to a matrix protein. Biochem. Biophys. Res. Commun. 1986;139:1195-1201.

79. Gasmi L, McLennan AG. The mouse Nudt7 gene encodes a peroxisomal nudix hydrolase specific for coenzyme A and its derivatives. Biochem. J. 2001;357:33-38.

80. Cartwright JL, Gasmi L, Spiller DG, McLennan AG. The Saccharomyces cerevisiae PCD1 gene encodes a peroxisomal nudix hydrolase active toward coenzyme A and its derivatives. J Biol Chem 2000;275:32925-32930.

81. AbdelRaheim SR, McLennan AG. The Caenorhabditis elegans Y87G2A.14 Nudix hydrolase is a peroxisomal coenzyme A diphosphatase. BMC Biochem 2002;3:5.

82. Ofman R, Speijer D, Leen R, Wanders RJA. Proteomic analysis of mouse kidney peroxisomes: identification of RP2p as a peroxisomal nudix hydrolase with acyl-CoA diphosphatase activity. Biochem. J. 2006;393:537-543.

83. Antonenkov VD, Sormunen RT, Hiltunen JK. The rat liver peroxisomal membrane forms a permeability barrier for cofactors but not for small metabolites in vitro. J. Cell Sci. 2004;117:5633-5642.

84. Palmieri L, Rottensteiner H, Girzalsky W, Scarcia P, Palmieri F, Erdmann R. Identification and functional reconstitution of the yeast peroxisomal adenine nucleotide transporter. EMBO J. 2001;20:5049-5059.

85. Visser WF, van Roermund CW, Waterham HR, Wanders RJ. Identification of human PMP34 as a peroxisomal ATP transporter. Biochem. Biophys. Res. Commun. 2002;299:494-497.

86. Leonardi R, Zhang Y-M, Rock C, Jackowski S. Coenzyme A: Back in action. Prog. Lipid Res. 2005;44:125-153.

87. Verkade PE, Van der Lee J. Researches on fat metabolism. II. Biochem. J. 1934;28:31-40.

88. Mortensen PB. The possible antiketogenic and gluconeogenic effect of the omega-oxidation of fatty acids in rats. Biochim. Biophys. Acta 1980;620:177-185.

89. Mortensen PB, Gregersen N. The biological origin of ketotic dicarboxylic aciduria. II. In vivo and in vitro investigations of the beta-oxidation of C8-C16dicarboxylic acids in unstarved, starved and diabetic rats. Biochim. Biophys. Acta 1982;710:477-484.

90. Bergseth S, Hokland BM, Bremer J. Metabolism of dicarboxylic acids in vivo and in the perfused kidney of the rat. Biochim. Biophys. Acta 1988;961:103-109.

91. Mortensen PB. C6-C10-dicarboxylic acids in liver and kidney tissue in normal, diabetic ketotic and clofibrate-treated rats. Biochim. Biophys. Acta 1986;878:14-19.

92. Sanders RJ, Ofman R, Valianpour F, Kemp S, Wanders RJA. Evidence for two enzymatic pathways for $\omega$-oxidation of docosanoic acid in rat liver microsomes. J. Lipid Res. 2005;46:1001-1008.

93. Björkhem I. On the mechanism of regulation of $\omega$-oxidation of fatty acids. J. Biol. Chem. 1976;251:5259-5266.

94. Kølvraa S, Gregersen N. In vitro studies on the oxidation of medium-chain dicarboxylic acids in rat liver. Biochim. Biophys. Acta 1986;876:515-525. 
95. Vamecq J, Draye JP, Brison J. Rat liver metabolism of dicarboxylic acids. Am. J. Physiol. 1989;256:G680-688.

96. Vamecq J, Draye JP. Peroxisomal and mitochondrial beta-oxidation of monocarboxylyl-CoA, omega-hydroxymonocarboxylyl-CoA and dicarboxylyl-CoA esters in tissues from untreated and clofibrate-treated rats. J. Biochem. (Tokyo) 1989;106:216-222.

97. Cerdan S, Künnecke B, Dölle A, Seelig J. In situ metabolism of 1,omega medium chain dicarboxylic acids in the liver of intact rats as detected by $13 \mathrm{C}$ and $1 \mathrm{H}$ NMR. J. Biol. Chem. 1988;263:11664-11674.

98. Mortensen PB, Kølvraa S, Gregersen N, Rasmussen K. Cyanide-insensitive and clofibrate enhanced beta-oxidation of dodecanedioic acid in rat liver. An indication of peroxisomal beta-oxidation of $\mathrm{N}$-dicarboxylic acids. Biochim. Biophys. Acta 1982;713:393-397.

99. Ferdinandusse S, Denis S, van Roermund CW, Wanders RJA, Dacremont G. Identification of the peroxisomal $\beta$-oxidation enzymes involved in the degreadation of long-chain dicarboxylic acids. J. Lipid Res. 2004;45:1104-1111.

100. Dirkx R, Meyhi E, Asselberghs S, Reddy J, Baes M, Van Veldhoven PP. $\beta$ oxidation in hepatocyte cultures from mice with peroxisomal gene knockouts. Biochem. Biophys. Res. Commun. 2007;357:718-723.

101. Gregersen N, Kølvraa S, Mortensen PB, Rasmussen K. C6-C10-dicarboxylic aciduria: biochemical considerations in relation to diagnosis of beta-oxidation defects. Scand. J. Clin. Lab. Invest. Suppl. 1982;161:15-27.

102. Sanders R-J, Ofman R, Dacremont G, Wanders RJA, Kemp S. Characterization of the human $\omega$-oxidation pathway for $\omega$-hydroxy-very-long-chain fatty acids. FASEB. J. 2008;22:epub 8 January 2008.

103. Sanders R-J, Ofman R, Duran M, Kemp S, Wanders RJA. Omega-oxidation of very long-chain fatty acids in human liver microsomes. Implications for X-linked adrenoleukodystrophy. J. Biol. Chem. 2006;281:13180-13187.

104. Björkhem I, Blomstrand S, Hågå P, Kase BF, Palonek E, Pedersen JI, Strandvik B, Wikström SA. Urinary excretion of dicarboxylic acids from patients with the Zellweger syndrome. Importance of peroxisomes in beta-oxidation of dicarboxylic acids. Biochem. Biophys. Acta 1984;795:15-19.

105. Rocchiccioli F, Aubourg P, Bougnéres PF. Medium- and long-chain dicarboxylic aciduria in patients with Zellweger syndrome and neonatal adrenoleukodystrophy. Pediatr. Res. 1986;20:62-66.

106. Korman SH, H. M, Gutman A. Characteristic urine organic acid profile in peroxisomal biogenesis disorders. J. Inherit. Metab. Dis. 2000;23:425-428.

107. Vamecq J, de Hoffmann E, van Hoof F. The microsomal dicarboxylyl-CoA synthetase. Biochem. J. 1985;230:683-693.

108. Jansen GA, Wanders RJA. Alpha-oxidation. Biochim. Biophys. Acta 2006;1763:1403-1412.

109. van den Brink DM, Wanders RJA. Phytanic acid: production from phytol, its breakdown and role in human disease. Cell. Mol. Life Sci. 2006;63:1752-1765.

110. Verhoeven NM, Jakobs C, Carney G, Somers MP, Wanders RJA, Rizzo WB. Involvement of microsomal fatty aldehyde dehydrogenase in the alpha-oxidation of phytanic acid. FEBS Lett. 1998;429:225-228. 
111. Ashibe G, Hirai T, Higashi K, Sekimizu K, Motojima K. Dual subcellular localization in the endoplasmic reticulum and peroxisomes and a vital role in protecting against oxidative stress of fatty aldehyde dehydrogenase are achieved by alternative splicing. J. Biol. Chem. 2007;282:20763-20773.

112. Schmitz W, Albers C, Fingerhut R, Conzelmann E. Purification and characterization of an alpha-methylacyl-CoA racemase from human liver. Eur. J. Biochem. 1995;231:815-822.

113. Ferdinandusse S, Denis S, Ijlst L, Dacremont G, Waterham HR, Wanders RJA. Subcellular localization and physiological role of $\alpha$-methylacyl-CoA racemase. J. Lipid Res. 2000;41:1890-1896.

114. Kotti TJ, Savolainen K, Helander HM, A. Y, Novikov DK, Kalkkinen N, Conzelmann E, Hiltunen JK, Schmitz W. In mouse alpha -methylacyl-CoA racemase, the same gene product is simultaneously located in mitochondria and peroxisomes. J. Biol. Chem. 2000;275:20887-20895.

115. Savolainen K, Kotti TJ, Schmitz W, Savolainen TI, Sormunen RT, Ilves M, Vainio SJ, Conzelmann E, Hiltunen JK. A mouse model for alpha-methylacyl-CoA racemase deficiency: adjustment of bile acid synthesis and intolerance to dietary methylbranched lipids. Hum. Mol. Genet. 2004;13:955-965.

116. Ferdinandusse S, Denis S, Clayton PT, Graham A, Rees JE, Allen JT, McLean BN, Y. BA, Vreken P, Waterham HR, J. WR. Mutations in the gene encoding peroxisomal alpha-methylacyl-CoA racemase cause adult-onset sensory motor neuropathy. Nat. Genet. 2000;24:188-191.

117. Mize CE, Avigan J, Baxter JH, Fales HM, Steinberg D. Metabolism of phytol-U14C and phytanic acid-U-14C in the rat. J. Lipid Res. 1966;7:684-691.

118. Le Bon AM, Cravedi JP, Tulliez JE. Disposition and metabolism of pristane in rat. Lipids 1988;23:424-429.

119. Kim HY. Novel metabolism of docosahexaenoic acid in neural cells. J. Biol. Chem. 2007;282:18661-18665.

120. Ferdinandusse S, Denis S, Mooijer PAW, Zhang Z, Reddy J, Spector AA, Wanders RJA. Identification of the peroxisomal $\beta$-oxidation enzymes involved in the biosynthesis of docosahexaenoic acid. J. Lipid Res. 2001;42:1987-1995.

121. Petroni A, Bertagnolio B, La Spada P, Blasevich M, Papini N, Govoni S, Rimoldi $\mathrm{M}$, Galli C. The beta-oxidation of arachidonic acid and the synthesis of docosahexaenoic acid are selectively and consistently altered in skin fibroblasts from three Zellweger patients versus X-adrenoleukodystrophy, Alzheimer and control subjects. Neurosci. Lett. 1998;250:145-148.

122. Ferdinandusse S, Denis S, Dacremont G, Wanders RJA. Studies on the metabolic fate of n-3 polyunsaturated fatty acids. J. Lipid Res. 2003;44:1992-1997.

123. Kase BF, Björkhem I, Pedersen JI. Formation of cholic acid from $3 \alpha, 7 \alpha, 12 \alpha-$ trihydroxy-5 $\beta$-cholestanoic acid by rat liver peroxisomes. J. Lipid Res. 1983;24:15601567.

124. Prydz K, Kase BF, Björkhem I, Pedersen JI. Formation of chenodeoxycholic acid from 3alpha,7alpha-dihydroxy-5beta-cholestanoic acid by rat liver peroxisomes. J. Lipid Res. 1986;27:622-628.

125. Kase BF, Pedersen JI, Wathne KO, Gustafsson J, Björkhem I. Importance of peroxisomes in the formation of chenodeoxycholic acid in human liver. Metabolism of 3 
alpha,7 alpha-dihydroxy-5 beta-cholestanoic acid in Zellweger syndrome. Pediatr. Res. 1991;29:64-69.

126. Kase BF, Pedersen JI, Strandvik B, Björkhem I. Defective peroxisomal cleavage of the C27-steroid side chain in the cerebro-hepato-renal syndrome of Zellweger. J. Clin. Invest. 1985;75:427-435.

127. Pedersen JI, Gustafsson J. Conversion of 3 alpha, 7 alpha, 12 alpha-trihydroxy-5 beta-cholestanoic acid into cholic acid by rat liver peroxisomes. FEBS Lett. 1980;121:345-348.

128. Falany CN, Fortinberry H, Leiter EH, Barnes S. Cloning, expression, and chromosomal localization of moue liver bile acid-CoA:amino acid $N$-acyltransferase. J. Lipid Res. 1997;38:1139-1148.

129. Falany CN, Johnson MR, Barnes S, Diasio RB. Glycine and taurine conjugation of bile acids by a single enzyme. Molecular cloning and expression of human liver bile acid-CoA:amino acid $N$-acyltransferase. J. Biol. Chem. 1994;269:19375-19379.

130. He D, Barnes S, Falany CN. Rat liver bile acid CoA:amino acid $N$ acyltransferase: expression, characterization, and peroxisomal localization. J. Lipid Res. 2003;44:2242-2249.

131. O'Byrne J, Hunt MC, Rai DK, Saeki M, Alexson SEH. The human bile acidCoA:amino acid $\mathrm{N}$-acyltransferase functions in conjugation of fatty acids to glycine. $\mathrm{J}$. Biol. Chem. 2003;278:34237-34344.

132. Killenberg PG, Jordan JT. Purification and characterization of bile acidCoA:amino acid $N$-acyltransferase from rat liver. J. Biol. Chem. 1978;253:1005-1010.

133. Scherstén T, Björntorp P, Ekdahl P-H, Björkerud S. The synthesis of taurocholic and glycocholic acids by preparations of human liver II. An analysis of the stimulating effect of the L fraction. Biochim. Biophys. Acta 1967;141:155-163.

134. Kase BF, Björkhem I. Peroxisomal bile acid-CoA:amino-acid $N$-acyltransferase in rat liver. J. Biol. Chem. 1989;264:9220-9223.

135. Styles NA, Falany JL, Barnes S, Falany CN. Quantification and regulation of the subcellular distribution of bile acid coenzyme A:amino acid $N$-acyltransferase activity in rat liver. J. Lipid Res. 2007;48:1305-1315.

136. Kwakye JB, Johnson MR, Barnes S, Grizzle WE, Diasio RB. Identification of bile acid-CoA:amino acid $N$-acyltransferase in rat kidney. Biochem. J. 1991;280:821-824.

137. Solaas K, Ulvestad A, Söreide O, Kase BF. Subcellular organization of bile acid amidation in human liver: a key issue in regulating the biosynthesis of bile salts. J. Lipid Res. 2000;41:1154-1162.

138. Solaas K, Sletta RJ, Søreide O, Kase BF. Presence of choloyl- and chenodeoxycholoyl-coenzyme A thioesterase activity in human liver. Scand. J. Clin. Invest. 2000;60:91-102.

139. Solaas K, Kase BF, Pham V, Bamberg K, Hunt MC, Alexson SEH. Differential regulation of cytosolic and peroxisomal bile acid amidation in mouse liver: PPAR alpha activation favors formation of unconjugated bile acids. J. Lipid Res. 2004;45:1051-1060.

140. Steinberg SJ, Mihalik SJ, G. KD, Cuebas DA, Watkins PA. The human liverspecific homolog of very long-chain acyl-CoA synthetase is cholate:CoA ligase. J. Biol. Chem. 2000;275:15605-15608.

141. Mihalik SJ, Steinberg SJ, Pei Z, Park J, Kim DG, Heinzer AK, Dacremont G, Wanders RJA, Cuebas DA, Smith KD, Watkins PA. Participation of two members of the 
very long-chain acyl-CoA synthetase family in bile acid synthesis and recycling. J. Biol. Chem. 2002;277:24771-24779.

142. Lametschwandtner G, Brocard C, Fransen M, Van Veldhoven P, Berger J, Hartig A. The difference in recognition of terminal tripeptides as peroxisomal targeting signal 1 between yeast and human is due to different affinities of their receptor Pex $5 p$ to the cognate signal and to residues adjacent to it. J. Biol. Chem. 1998;273:33635-33643.

143. Pellicoro A, van den Heuvel FA, Geuken M, Moshage H, Jansen PL, Faber KN. Human and rat bile acid-CoA:amino acid $N$-acyltransferase are liver-specific peroxisomal enzymes: implications for intracellular bile salt transport. Hepatology 2007;45:340-348.

144. Ferdinandusse S, Houten SM. Peroxisomes and bile acid biosynthesis. Biochim. Biophys. Acta 2006;1763:1427-1440.

145. Sfakianos MK, Wilson L, Sakalian M, Falany CN, Barnes S. Conserved residues in the putative catalytic triad of human bile acid coenzyme A:amino acid $\mathrm{N}$ acyltransferase. J. Biol. Chem. 2002;277:47270-47275.

146. Reilly S-J, O'Shea EM, Andersson U, O'Byrne J, Alexson SEH, Hunt MC. A peroxisomal acyltransferase in mouse identifies a novel pathway for taurine conjugation of fatty acids. FASEB J. 2007;21:99-107.

147. Carlton VE, Harris BZ, Puffenberger EG, Batta AK, Knisely AS, Robinson DL, Strauss KA, Shneider BL, Lim WA, Salen G, Morton DH, N. BL. Complex inheritance of familial hypercholanemia with associated mutations in TJP2 and BAAT. Nat. Genet. 2003;34:91-96.

148. Saghatelian A, Trauger SA, Want EJ, Hawkins EG, Siuzdak G, Cravatt BF. Assignment of endogenous substrates to enzymes by global metabolite profiling. Biochemistry 2004;43:14332-14339.

149. Saghatelian A, Cravatt BF. Discovery metabolite profiling - forging functional connections between the proteome and metabolome. Life Sciences 2005;77:1759-1766.

150. McKinney MK, Cravatt BF. Structure and function of fatty acid amide hydrolase. Annu. Rev. Biochem. 2005;2005:411-432.

151. Saghatelian A, McKinney MK, Bandell M, Patapoutian A, Cravatt BF. A FAAHregulated class of $\mathrm{N}$-acyl taurines that activates TRP Ion Channels. Biochemistry 2006;45:9007-9015.

152. Cohen DM. The transient receptor potential vanilloid-responsive 1 and 4 cation channels: role in neuronal osmosensing and renal physiology. Curr. Opin. Nephrol. Hypertens. 2007;16:451-458.

153. Boberg M, Angerbauer R, Kanhai WK, Karl W, Kern A, Radtke M, Steinke W. Biotransformation of cerivastatin in mice, rats and dogs in vivo. Drug Metab. Dispos. 1998;26:640-652.

154. Hankin JA, Wheelan P, Murphy RC. Identification of novel metabolites of prostaglandin $\mathrm{E}_{2}$ formed by isolated rat hepatocytes. Arch. Biochem. Biophys. 1997;340:317-330.

155. Li YT, Maskos K, Chou CW, Cole RB, Li SC. Presence of an unusual GM2 derivative, taurine-conjugated GM2, in Tay-Sachs brain. J. Biol. Chem. 2003;278:3528635291.

156. Van Veldhoven PP, Vanhove G, Asselberghs S, Eyssen HJ, Mannaerts GP. Substrate specificities of rat liver peroxisomal acyl-CoA oxidases: palmitoyl-CoA oxidase (inducible acyl-CoA oxidase), pristanoyl-CoA oxidase (non-inducible acyl-CoA 
oxidase), and trihydroxycoprostanoyl-CoA oxidase. J. Biol. Chem. 1992;267:2006520074.

157. Rakhshandehroo M, Sanderson LM, Matilainen M, Stienstra R, Carlberg C, de Groot PJ, Müller M, Kersten S. Comprehensive Analysis of PPAR-Dependent Regulation of Hepatic Lipid Metabolism by Expression Profiling. PPAR Res. 2007;26839:1-13.

158. Ebisuno S, Isohashi F, Nakanishi Y, Sakamoto Y. Acetyl-CoA hydrolase: relation between activity and cholesterol metabolism in rat. Am. J. Physiol. 1988;255:R724-730.

159. Zhang Y-M, Chohnan S, Virga KG, Stevens RD, Ilkayeva OR, Wenner BR, Bain JR, Newgard CB, Lee RE, Rock CO, Jackowski S. Chemical knockout of pantothenate kinase reveals the metabolic and genetic program responsible for hepatic coenzyme A homeostasis. Chem. Biol. 2007;14:291-302.

160. Lee J, Xu Y, Chen Y, Sprung R, Chan Kim S, Shanhai X, Zhao Y. Mitochondrial phosphoproteome revealed by an improved IMAC method and MS/MS/MS. Mol. Cell. Proteomics 2007;6:669-676.

161. Pircher PC, Kitto JL, Petrowski ML, Tangirala RK, Bischoff ED, Schulman JG, Westin SK. Farnexoid X receptor regulates bile acid-amino acid conjugation. J. Biol. Chem. 2003;278:27703-27711.

162. Inoue Y, Ai-Ming Y, Inoue J, Gonzalez F. Hepatocyte nuclear factor $4 \alpha$ is a central regulator of bile acid conjugation. J. Biol. Chem. 2004;279:2480-2489.

163. Chen YH, Hong IC, Kuo KK, Hsu HK, Hsu C. Role of retinoid-X receptor-alpha in the suppression of rat bile acid coenzyme A-amino acid $\mathrm{N}$-acyltransferase in liver during sepsis. Shock 2007;28:65-70.

164. Zomer AWM, van der Burg B, Jansen GA, Wanders RJA, Poll-The BT, van der Saag PT. Pristanic acid and phytanic acid: naturally occurring ligands for the nuclear receptor peroxisome proliferator-activated receptor $\alpha$. J. Lipid Res. 2000;41:1801-1807. 


\section{Figure Legends}

Figure. 1. The reactions catalyzed by acyl-CoA thioesterases (ACOTs) and acylCoA:amino acid $N$-acyltransferases (ACNAT and BAAT). ACOTs hydrolyze the CoA ester of various fatty acids into the free fatty acid + coenzyme A (CoASH). The substrate shown is stearoyl-CoA $\left(\mathrm{C}_{18}-\mathrm{CoA}\right)$ but can be long-chain, medium-chain, shortchain, branched-chain, bile acid-CoAs or dicarboxylyl-CoAs, depending on the ACOT enzyme involved. (B) The reaction catalyzed by acyl-CoA:amino acid $N$-acyltransferase (ACNAT) is the conjugation (or amidation) of fatty acids (long-chain and very longchain) to taurine, resulting in the production of an $\mathrm{N}$-acyltaurine. The substrate shown is stearoyl-CoA $\left(\mathrm{C}_{18}-\mathrm{CoA}\right)(\mathrm{C})$ The bile acid-CoA:amino acid $N$-acyltransferase (BAAT) catalyzes the conjugation (amidation) of bile acids to glycine or taurine, resulting in a conjugated bile acid. Choloyl-CoA is shown as the substrate, with glycine as the acceptor, resulting in the formation of choloylglycine. Human BAAT can also conjugate fatty acids to glycine or taurine as shown in the reaction in (B) above.

Figure 2. The Type-I acyl-CoA thioesterase gene cluster in human and mouse. The Type-I human acyl-CoA thioesterases are localized in a cluster on human chromosome 14q24.3, encoding two cytosolic, one mitochondrial and one peroxisomal enzyme (ACOT4). The peroxisomal ACOT4 contains a carboxyterminal -PKL, which functions as a peroxisomal targeting signal. In mouse, a similar cluster is found on chromosome 12 D3, containing four peroxisomal Acots $(A \cot 3,4,5$ and 6$)$, one mitochondrial and one 
cytosolic gene. Each of the four peroxisomal ACOTs contain a peroxisomal targeting signal of -CRL, -AKL, or -SKL.

Figure 3. Routes for excretion of fatty acids from peroxisomes. Very long-chain fatty acids (VLCFA), bile acid intermediates, methyl branched fatty acids and dicarboxylic acids enter the peroxisome, likely as the CoA ester, via $\mathrm{ABC}$ half transporters. $\mathrm{ABCD} 1$ transports VLCFAs into peroxisomes and ABCD3 may be involved in transport of bile acid-CoA intermediates and branched chain CoA esters. It is not yet known which ABC protein is involved in transport of dicarboxylyl-CoA esters. These CoA esters then undergo $\beta$-oxidation in peroxisomes, involving a dehydrogenation (catalyzed by an acylCoA oxidase), hydration/dehydrogenation (catalyzed by a bifunctional enzyme) and a thiolytic cleavage (catalyzed by a thiolase). CoASH is required for the thiolase reaction, resulting in a chain-shortened CoA ester plus acetyl-CoA or propionyl-CoA, depending on the substrate. There are three potential pathways for these chain shortened products; esterification to carnitine catalyzed by carnitine acyltransferases (CRAT and CROT), hydrolysis to the free acid by acyl-CoA thioesterases (ACOTs) or to the acyl-4'phosphopantetheine by nudix hydrolases (NUDT7 or NUDT19), or conjugation (amidation) to glycine or taurine by the bile acid-CoA:amino acid $\mathrm{N}$-acyltransferase (BAAT), or to taurine by the acyl-CoA:amino acid $N$-acyltransferases (ACNAT1 and ACNAT2). These products may then be transported to mitochondria for further oxidation or excreted directly in urine or bile. 
Figure 4. Schematic representation of the roles of ACOTs, carnitine acyltransferases and nudix hydrolases in peroxisomal $\alpha$ - and $\beta$-oxidation. Very long-chain fatty acids (VLCFA) are transported into the peroxisome via the ABCD1 transporter and undergo $\beta$ oxidation to produce chain-shortened acyl-CoAs, with the concomitant release of acetylCoA. These very long chain acyl-CoAs can be hydrolyzed to the free fatty acid and CoASH by ACOT3, or alternatively may be further $\beta$-oxidized to medium chain acylCoAs (MC-CoA). ACOT5 and CROT are both active on medium chain acyl-CoAs, resulting in production of the free acid (MCFA) or carnitine ester (MC-carn), depending on the tissue involved [28]. These long chain/medium chain fatty acids or carnitine esters may be transported to the mitochondria for further oxidation. Long chain dicarboxylic acids (LC-DCA) are transported into the peroxisome, likely as the CoA ester through an as yet unidentified $\mathrm{ABCD}$ transporter and undergo $\beta$-oxidation, resulting in medium chain dicarboxylyl-CoAs (MC-DCA), which are substrates for ACOT8, or alternatively are further $\beta$-oxidized to a $\mathrm{C} 4$ succinyl-CoA. As succinyl-CoA cannot be converted to a carnitine ester, it is hydrolyzed by the action of ACOT4, resulting in production of succinate, which is excreted in urine. The acetyl-CoA produced by $\beta$-oxidation can be a substrate for either the short chain carnitine acetyltransferase (CRAT) or the short chain acyl-CoA thioesterase (ACOT12), resulting in production of the free acid or carnitine ester, depending on the tissue involved [28]. The acetate will go the cytosolic pool of acetate, whereas the acetylcarnitine will be transported to the mitochondria for further oxidation. The metabolism of CoASH in peroxisomes occurs by the action of Nudix hydrolases, NUDT7 and NUDT19, which hydrolyze free CoASH to 3',5'-ADP and 4'phosphopantetheine. Recent data also indicates that these enzymes hydrolyze bile acid- 
CoA esters, long-chain, medium-chain and short-chain acyl-CoAs to 3',5'-ADP and acyl4'-phosphopantetheine, however the physiological significance of this activity is not yet fully understood. For simplicity, only the reaction of NUDT7 and NUDT19 with free CoA is shown. The substrates and the enzymes are involved are colour-coded.

Figure 5. ACOT4 and ACOT8 both hydrolyze dicarboxylyl-CoA esters but with different specificities. Thioesterase activity of recombinantly expressed ACOT4 and ACOT8 were measured with short and medium chain dicarboxylyl-CoAs at $25 \mu \mathrm{M}$. Data are shown as mean \pm S.E.M. Figure reproduced with permission from J. Biol. Chem. [25].

Figure 6. The role of ACOT6 in methyl branched acyl-CoA metabolism in peroxisomes. Phytanoyl-CoA enters peroxisomes, possibly through the ABCD3 transporter. The $\alpha$-oxidaiton of phytanoyl-CoA to pristanoyl-CoA results in conversion of a 3-methyl branched fatty acid to a 2-methyl branched fatty acid, which is then a substrate for $\beta$-oxidation. Pristanoyl-CoA undergoes 3 cycles of $\beta$-oxidation, resulting in the production of dimethylnonanoyl-CoA (DMN-CoA), which can either be esterified to carnitine by CROT, or alternatively hydrolyzed to the free acid by ACOT8 or ACOT5, and be further oxidized in mitochondria. Propionyl-CoA and acetyl-CoA are produced from the $\beta$-oxidation of methyl branched fatty acids, which will be substrates for CRAT or ACOT12. The acetate/propionate will go the cytosolic pool, whereas the acetylcarnitine/propionylcarnitine will be transported to the mitochondria for further oxidation. ACOT6 can hydrolyze pristanoyl-CoA and phytanoyl-CoA directly to the free 
acid, allowing for esterification of pristanic and phytanic into triglycerides (TAG). ACOT6 is active in white adipose tissue to hydrolyze the $2 \mathrm{R}$ isomer of pristanoyl-CoA to pristanic acid, which can then go to liver to be converted to the $2 \mathrm{~S}$ isomer by the AMACR (see section 3.1.4 for further details) and be $\beta$-oxidized. Pristanic and phytanic acid are ligands for the PPAR $\alpha$ [164], thus ACOT6 may also function in ligand supply for this nuclear receptor, as discussed in [27].

Figure 7. The acyltransferase gene cluster in human and mouse. Human contains an acyltransferase gene cluster localized on chromosome 9q31.1, encoding for the bile acidCoA:amino acid $N$-acyltransferase (BAAT) enzyme and a further acyl-CoA:amino acid $N$-acyltransferase (ACNAT) pseudogene. BAAT contains a variant of the peroxisomal targeting signal -SQL, whereas the ACNAT pseudogene contains -SKL. The ACNAT pseudogene contains in-frame stop codons that will not translate into a functional protein. In mouse, a related gene cluster on chromosome 4 B3 contains three acyltransferase genes Baat, Acnatl and Acnat2. BAAT contains a variant of the peroxisomal targeting signal, ending -SQL, whereas ACNAT1 and ACNAT2 contain canonical peroxisomal targeting signals -SKL at their carboxyterminal ends.

Figure 8. Schematic representation of the roles of acyltranserases in peroxisomal lipid metabolism. The final step in the formation of the primary bile acids, choloyl-CoA and chenodeoxycholoyl-CoA involves one cycle of $\beta$-oxidation in peroxisomes, resulting in the formation of a $\mathrm{C} 24$ bile acid from a C27 bile acid trihydroxycoprostanoyl-CoA (THCA-CoA) or dihydroxycoprostanoyl-CoA (DHCA-CoA), with the concomitant 
release of propionyl-CoA. These $\mathrm{C} 27$ bile acids may enter the peroxisome via the ABCD3 transporter. The conjugation (amidation) to glycine or taurine is carried out by BAAT to produce a glyco- or tauro-conjugated bile acid, which is then excreted in bile. ACOT8 can also hydrolyze the CoA esters of choloyl-CoA and chenodeoxycholoyl-CoA, resulting in free bile acids cholic acid (CA) and chenodeoxycholic acid (CDCA), however the physiological function of this enzyme in bile acid synthesis is not yet clear. Very long-chain fatty acids (VLCFA) are transported into the peroxisome via the ABCD1 transporter and undergo $\beta$-oxidation, to produce chain-shortened acyl-CoAs, with the concomitant release of acetyl-CoA. These very long chain and long chain acyl-CoAs are substrates for conjugation (amidation) to taurine by ACNAT1, resulting in the production of an $N$-acyltaurine. These $N$-acyltaurines can then be excreted in urine or bile, or be transported in blood to other tissues. $\mathrm{N}$-acyltaurines have also been shown to activate the transient receptor potential ion channels TRPV1 and TRPV4 [151]. Human BAAT has also been shown to conjugate long-chain and very long-chain acyl-CoAs to glycine and taurine [131], but it is not known if the mouse or rat BAAT have this activity. The propionyl-CoA or acetyl-CoA produced by $\beta$-oxidation can be substrates for either the short chain carnitine acetyltransferase (CRAT) or the short chain acyl-CoA thioesterase (ACOT12), resulting in production of the free acid or carnitine ester, depending on the tissue involved [28]. The acetate/propionate will go the cytosolic pool, whereas the acetylcarnitine/propionylcarnitine will be transported to the mitochondria for further oxidation. 
Table I. Characteristics of peroxisomal acyl-CoA thioesterases and acyltranserases identified in mouse. The peroxisomal targeting signal shown as a tripeptide at the carboxyterminal end is indicated. Acot: acyl-CoA thioesterase; Baat: bile acidCoA:amino acid $N$-acyltransferase; Acnat: acyl-CoA: amino acid $N$-acyltransferase; Prox: proximal; WAT: white adipose tissue

\begin{tabular}{|c|c|c|c|c|c|}
\hline Gene & $\begin{array}{l}\text { Carboxy } \\
\text { terminal } \\
\text { sequence }\end{array}$ & $\begin{array}{l}\text { Previous } \\
\text { nomenclature } \\
\text { and aliases }\end{array}$ & $\begin{array}{l}\text { Substrate (CoA } \\
\text { ester) } \\
\text { [reference] }\end{array}$ & $\begin{array}{l}\text { Chromosome } \\
\text { and } \\
\text { accession } \\
\text { number }\end{array}$ & $\begin{array}{l}\text { Tissue } \\
\text { expression }\end{array}$ \\
\hline Acot3 & $-\mathrm{AKL}$ & PTE-Ia & Long chain [26] & $\begin{array}{l}12 \text { D3 } \\
\text { NP_599007 }\end{array}$ & Kidney \\
\hline Acot4 & -CRL & PTE-Ib, Pte2b & $\begin{array}{l}\text { Succinyl, glutaryl } \\
{[25]}\end{array}$ & $\begin{array}{l}12 \text { D3 } \\
\text { NP_599008 }\end{array}$ & $\begin{array}{l}\text { Liver, } \\
\text { kidney }\end{array}$ \\
\hline Acot5 & $-\mathrm{AKL}$ & PTE-Ic & Medium chain [26] & $\begin{array}{l}12 \text { D3 } \\
\text { NP_663419 }\end{array}$ & $\begin{array}{l}\text { Brain, } \\
\text { WAT }\end{array}$ \\
\hline Acot6 & -SKL & PTE-Id & $\begin{array}{l}\text { Pristanoyl/phytanoyl } \\
\text { [27] }\end{array}$ & $\begin{array}{l}12 \text { D3 } \\
\text { NP_766168 }\end{array}$ & $\begin{array}{l}\text { WAT, } \\
\text { Kidney, } \\
\text { Liver }\end{array}$ \\
\hline Acot 8 & -SKL & $\begin{array}{l}\text { PTE-2, hTE, } \\
\text { hACTEIII, } \\
\text { PTE1 }\end{array}$ & $\begin{array}{l}\text { All tested CoA } \\
\text { esters }[25,37,38]\end{array}$ & $\begin{array}{l}2 \mathrm{H} 3 \\
\text { NP_573503 }\end{array}$ & $\begin{array}{l}\text { Ubiquitous } \\
\text { - mainly } \\
\text { Prox. } \\
\text { Intestine, } \\
\text { Kidney, } \\
\text { Liver }\end{array}$ \\
\hline Acot12 & $-\mathrm{SVL}$ & $\begin{array}{l}\text { CACH-1, } \\
\text { MGC105114 } \\
\text { mCACH-1, } \\
\text { CACH }\end{array}$ & $\begin{array}{l}\text { Short chain } \\
\text { [44] }\end{array}$ & $\begin{array}{l}13 \mathrm{C} 3 \\
\text { NP_083066 }\end{array}$ & $\begin{array}{l}\text { Prox. } \\
\text { Intestine, } \\
\text { Liver, } \\
\text { Kidney }\end{array}$ \\
\hline Baat & -SQL & BACAT, BAT & $\begin{array}{l}\text { Bile acids } \\
{[128]}\end{array}$ & $\begin{array}{l}\text { 4 B3 } \\
\text { NP_031545 }\end{array}$ & Liver \\
\hline Acnatl & -SKL & & $\begin{array}{l}\text { Long chain/very } \\
\text { long chain [146] }\end{array}$ & $\begin{array}{l}\text { 4 B1 } \\
\text { ABE98441 }\end{array}$ & $\begin{array}{l}\text { Liver, } \\
\text { Kidney }\end{array}$ \\
\hline Acnat2 & -SKL & & Unknown & $\begin{array}{l}4 \text { B1 } \\
\text { (not yet } \\
\text { available) }\end{array}$ & Kidney \\
\hline
\end{tabular}


Table II. Characteristics of peroxisomal acyl-CoA thioesterases and acyltranserases identified in human. The peroxisomal targeting signal shown as a tripeptide at the carboxyterminal end is indicated. Acot: acyl-CoA thioesterase; Baat: bile acidCoA:amino acid $\mathrm{N}$-acyltransferase.

\begin{tabular}{|c|c|c|c|c|c|}
\hline Gene & $\begin{array}{l}\text { Carboxy } \\
\text { terminal } \\
\text { sequence }\end{array}$ & $\begin{array}{l}\text { Previous } \\
\text { nomenclature } \\
\text { and aliases }\end{array}$ & $\begin{array}{l}\text { Substrate } \\
\text { (CoA ester) } \\
\text { [reference] }\end{array}$ & $\begin{array}{l}\text { Chromosome } \\
\text { and accession } \\
\text { number }\end{array}$ & $\begin{array}{l}\text { Tissue } \\
\text { expression }\end{array}$ \\
\hline ACOT4 & -PKL & $\begin{array}{l}\text { PTE-1b, PTE- } \\
\text { 2b,hPTE-1 }\end{array}$ & $\begin{array}{l}\text { Succinyl, } \\
\text { glutaryl, } \\
\text { long chain } \\
\text { [29] }\end{array}$ & $\begin{array}{l}\text { 14q24.3 } \\
\text { NP_689544 }\end{array}$ & $\begin{array}{l}\text { Kidney, } \\
\text { Liver }\end{array}$ \\
\hline ACOT8 & -SKL & $\begin{array}{l}\text { PTE-2, hTE, } \\
\text { hACTEIII, } \\
\text { PTE1 }\end{array}$ & $\begin{array}{l}* * \text { medium } \\
\text { and long } \\
\text { chain [32] }\end{array}$ & $\begin{array}{l}\text { 20q12-q13.1 } \\
\text { NP_005460 }\end{array}$ & Ubiquitous\# \\
\hline ACOT12 & $-\mathrm{SKF} *$ & $\begin{array}{l}\text { CACH-1, } \\
\text { MGC105114 } \\
\text { mCACH-1, } \\
\text { CACH }\end{array}$ & $\begin{array}{l}\text { Short chain } \\
{[45]}\end{array}$ & $\begin{array}{l}5 q 14.1 \\
\text { NP_570123 }\end{array}$ & Liver\# \\
\hline$B A A T$ & -SQL & BACAT, BAT & $\begin{array}{l}\text { Bile acids, } \\
\text { long } \\
\text { chain/very } \\
\text { long chain } \\
{[129,131]}\end{array}$ & $\begin{array}{l}\text { 9q22.3 } \\
\text { NP_001692 }\end{array}$ & $\begin{array}{l}\text { Liver, } \\
\text { Gallbladder } \\
\text { mucosa }\end{array}$ \\
\hline
\end{tabular}

* Peroxisomal localization not confirmed

** Activity only tested with saturated acyl-CoA. As the mouse and rat enzymes are active on a broad range of acyl-CoAs, it is likely that the human enzyme has a similar broad substrate specificity. \# Based on GEO Profiles (http://www.ncbi.nlm.nih.gov) 
A

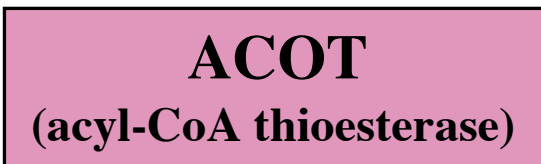

Fig. 1

$\mathrm{MmC}_{\mathrm{M}-\mathrm{S}-\mathrm{CoA}+\mathrm{H}_{2} \mathrm{O}}$

\section{ACNAT}

(acyl-CoA:amino acid

$\mathrm{N}$-acyltransferase)

B

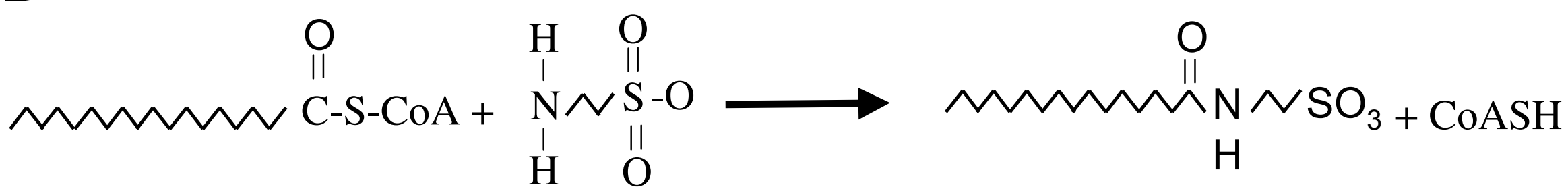

\section{BAAT}

C

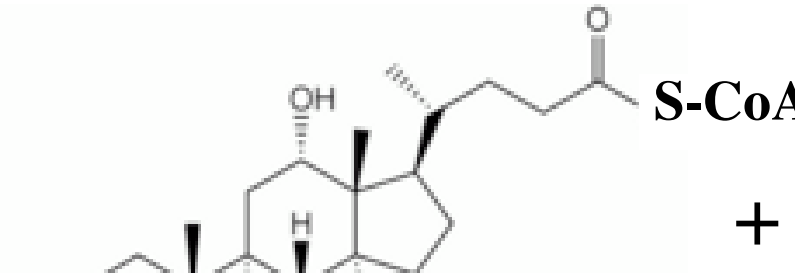

$+$

(bile acid-CoA:amino acid

$\mathrm{N}$-acyltransferase)

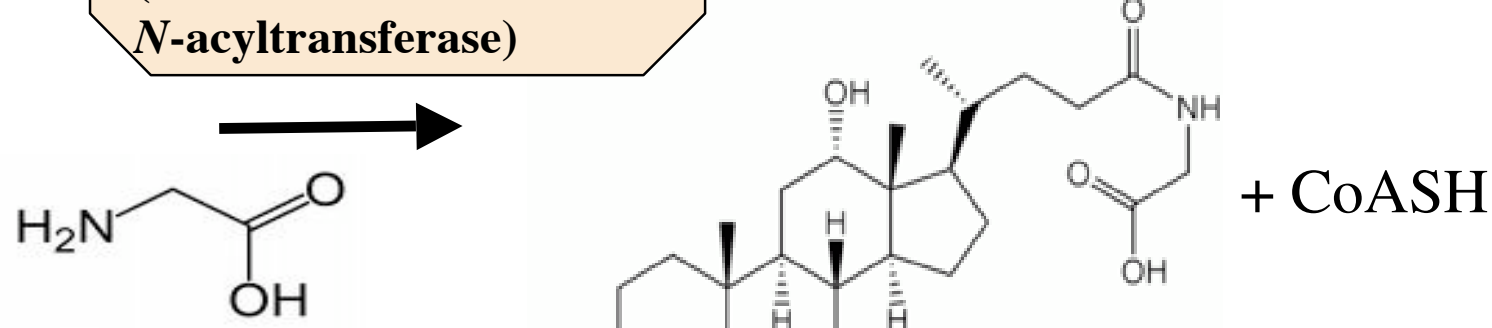

$\mathrm{HO}_{\mathrm{H}} \mathrm{N}^{\mathrm{N}} \mathrm{\textrm {OH }}$

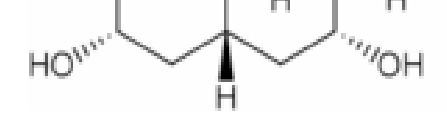




\section{Acot gene clusters}

Chromosome 14q24.3

\section{Human}

Chr. 14 (413)

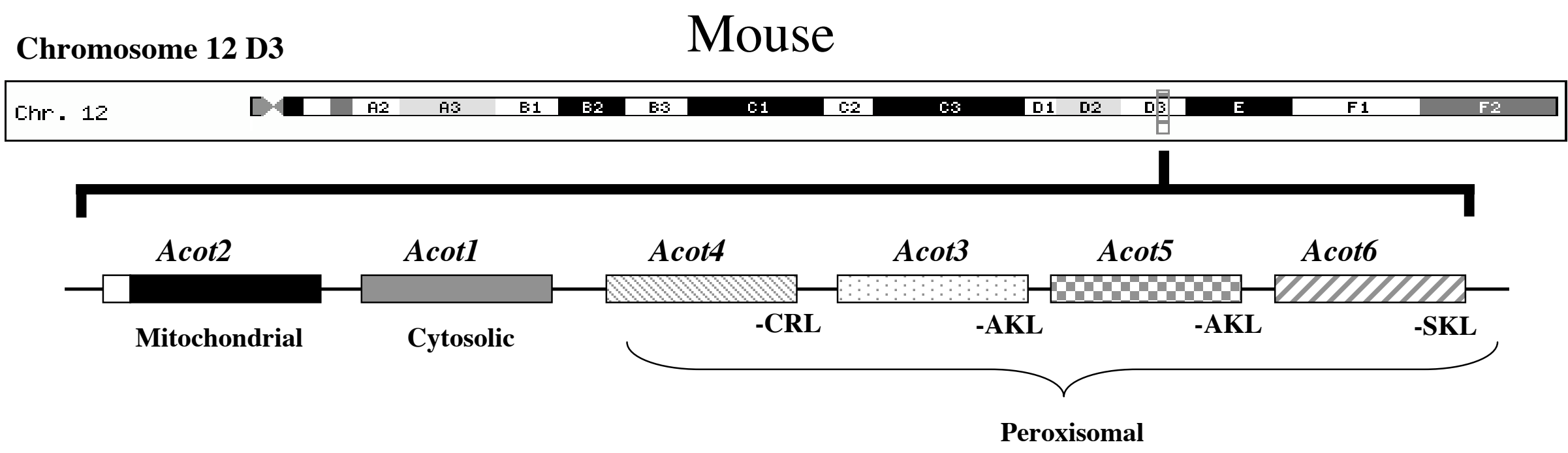




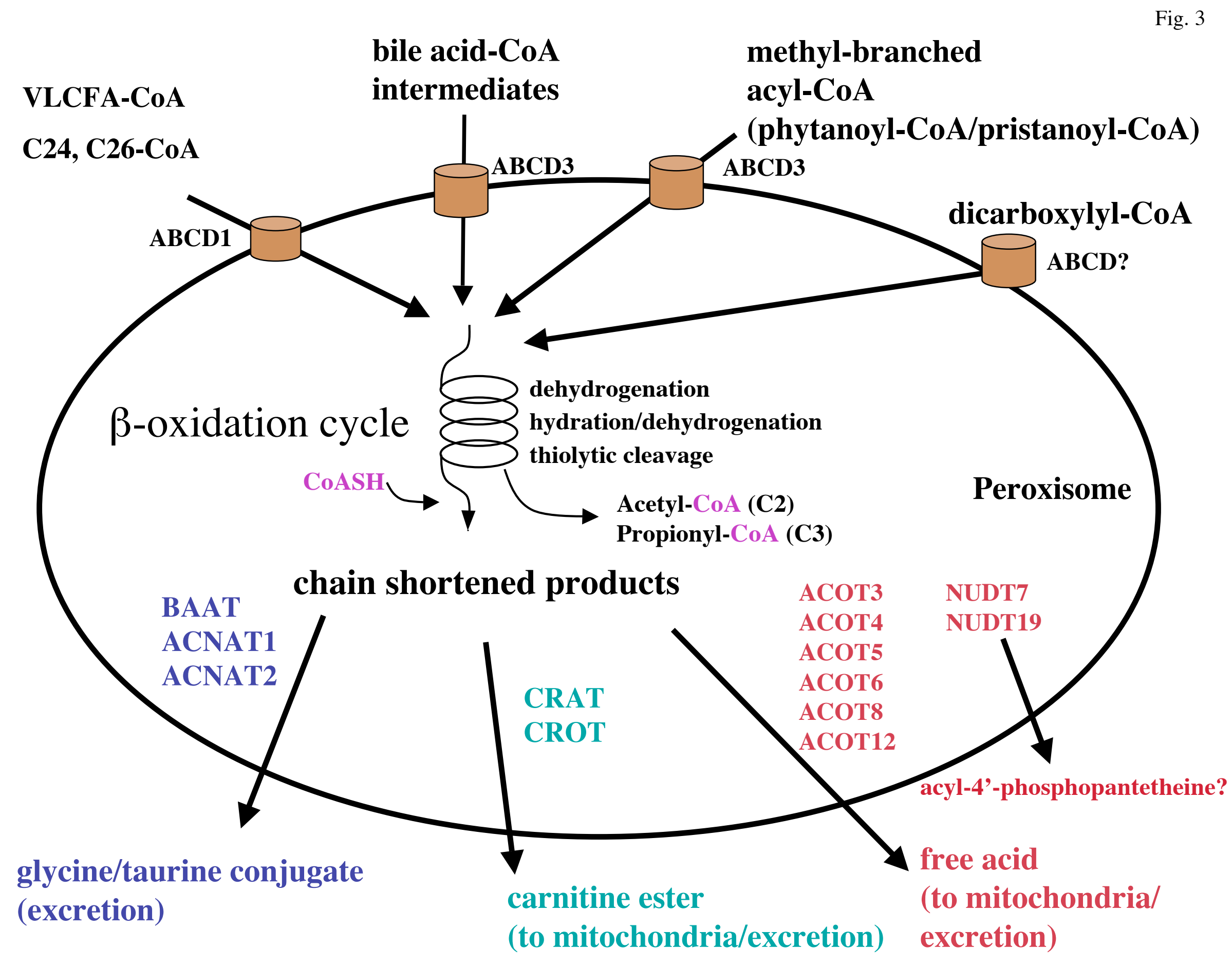


A

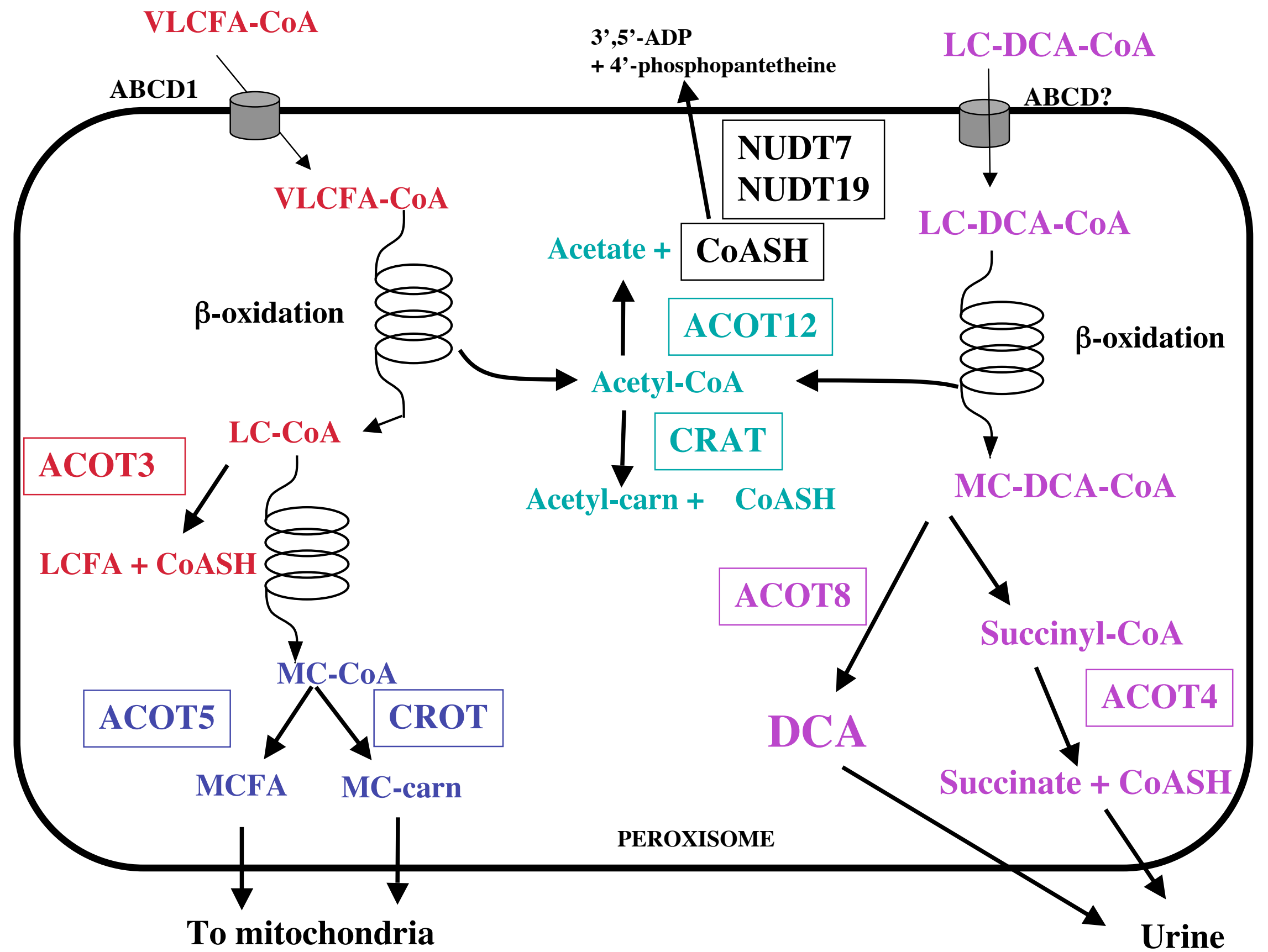


Fig. 5

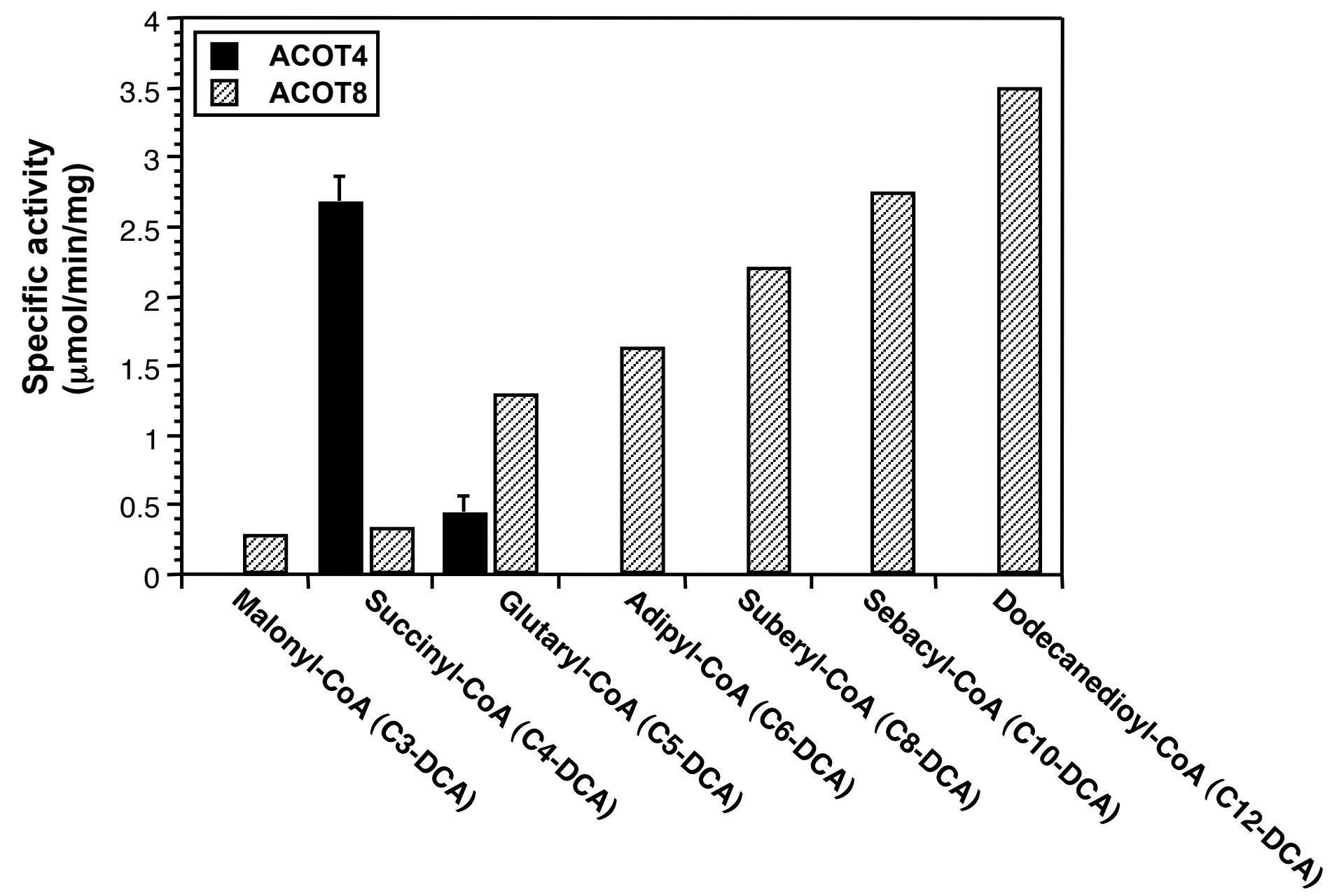




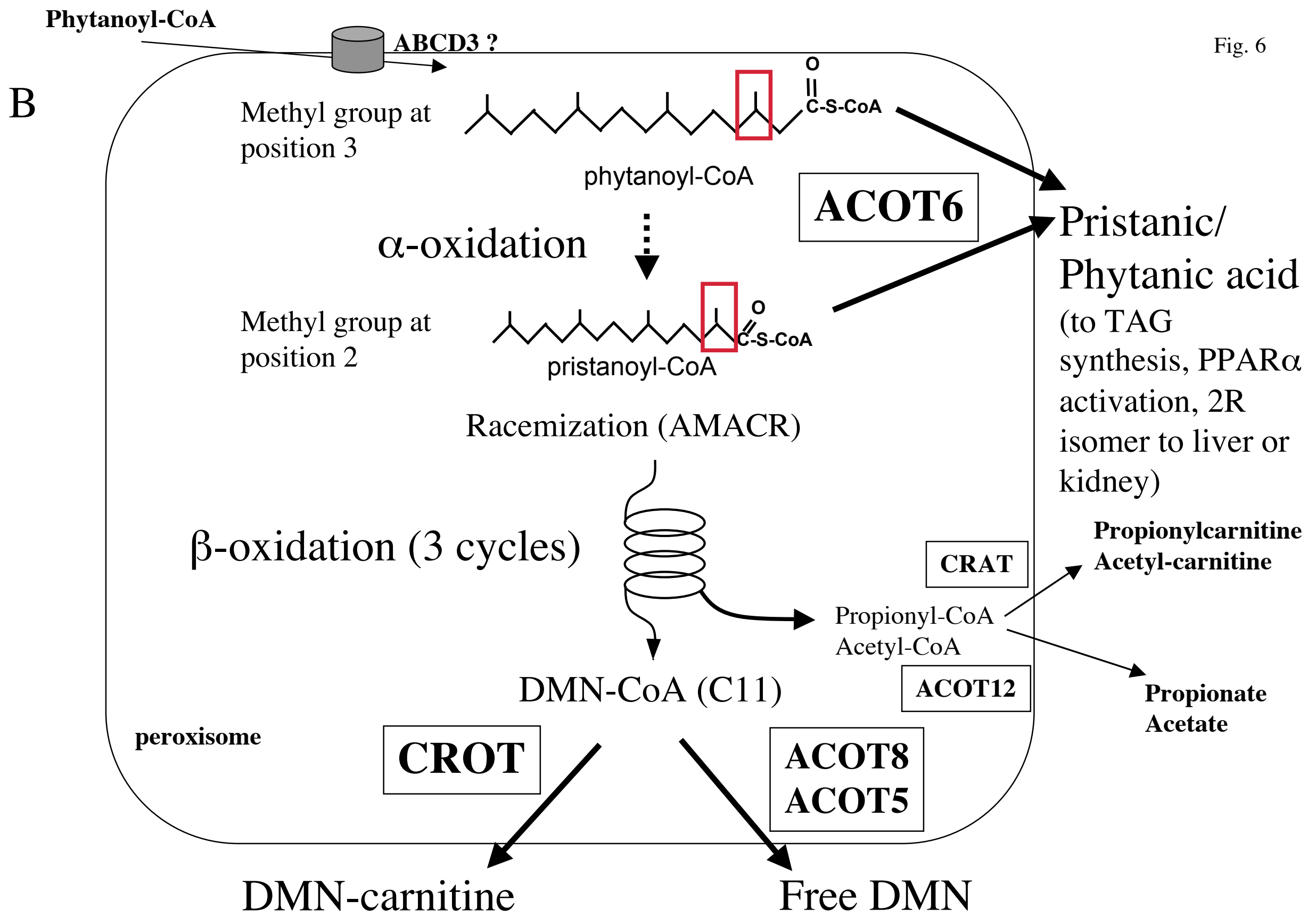

To mitochondria 


\section{Acyltransferase gene clusters}

\section{Human}

Chromosome 9q31.1

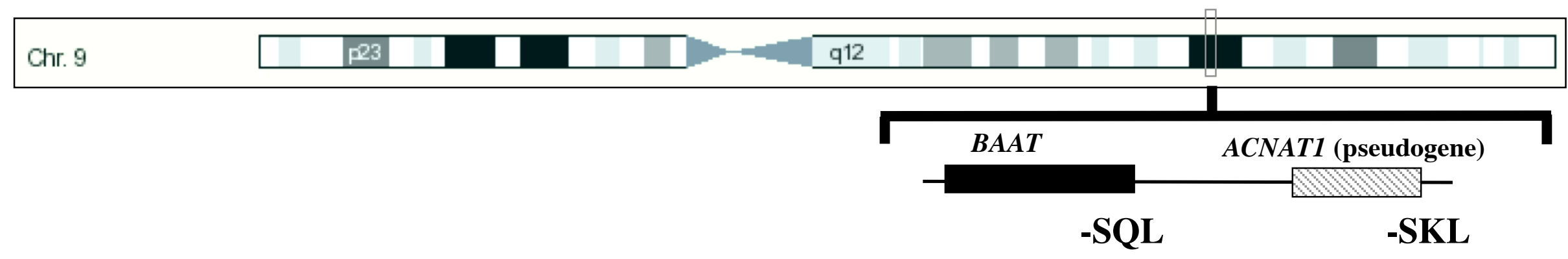

\section{Mouse}

Chromosome 4 B3

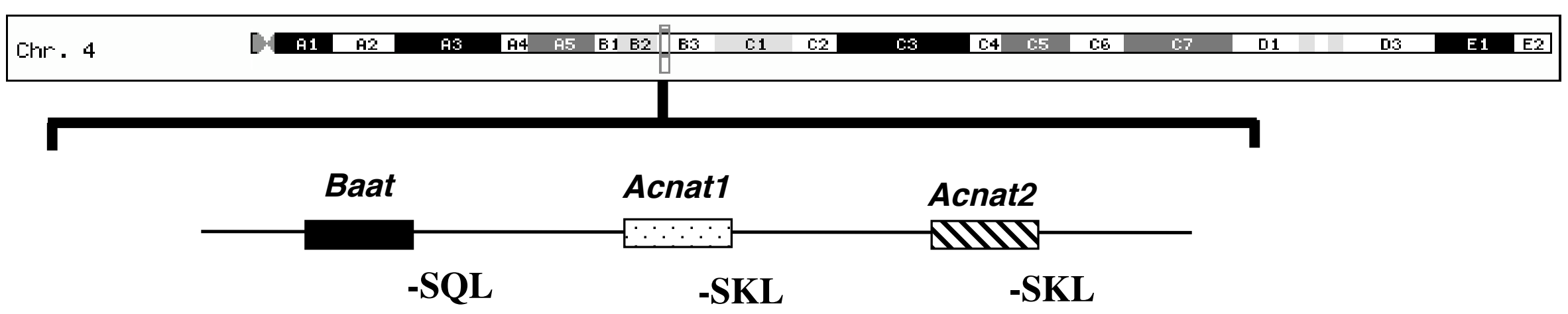




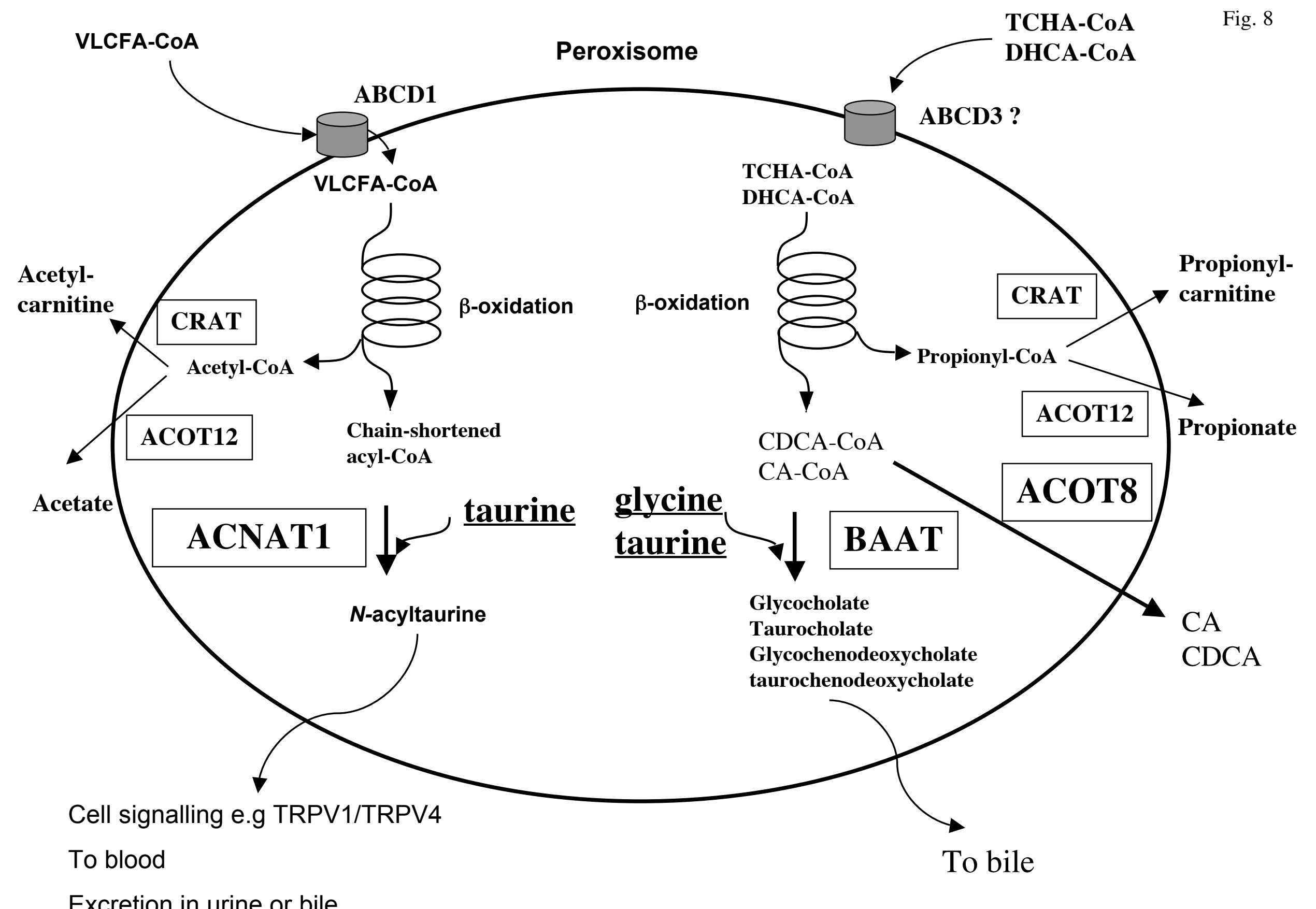

